\title{
A review of carbon-based and non-carbon-based catalyst supports for the selective catalytic reduction of nitric oxide
}

\author{
Shahreen Binti Izwan Anthonysamy, Syahidah Binti Afandi, Mehrnoush Khavarian \\ and Abdul Rahman Bin Mohamed ${ }^{\star} \S$
}

\author{
Review \\ Address: \\ School of Chemical Engineering, Universiti Sains Malaysia, \\ Engineering Campus, 14300 Nibong Tebal, Penang, Malaysia \\ Email: \\ Abdul Rahman Bin Mohamed - chrahman@usm.my \\ * Corresponding author \\ § Tel.: +604 599 6410; Fax: +604 5996908 \\ Keywords: \\ carbon-based catalyst support; Eley-Riedeal mechanism; \\ Langmuir-Hinshelwood mechanism; nitric oxide; non-carbon-based \\ catalyst support; selective catalytic reduction \\ Open Access \\ Beilstein J. Nanotechnol. 2018, 9, 740-761. \\ doi:10.3762/bjnano.9.68 \\ Received: 30 September 2017 \\ Accepted: 18 January 2018 \\ Published: 27 February 2018 \\ This article is part of the Thematic Series "Energy conversion, storage \\ and environmental remediation using nanomaterials". \\ Guest Editor: W.-J. Ong \\ (C) 2018 Anthonysamy et al.; licensee Beilstein-Institut. \\ License and terms: see end of document.
}

\begin{abstract}
Various types of carbon-based and non-carbon-based catalyst supports for nitric oxide (NO) removal through selective catalytic reduction (SCR) with ammonia are examined in this review. A number of carbon-based materials, such as carbon nanotubes (CNTs), activated carbon (AC), and graphene (GR) and non-carbon-based materials, such as Zeolite Socony Mobil-5 (ZSM-5), $\mathrm{TiO}_{2}$, and $\mathrm{Al}_{2} \mathrm{O}_{3}$ supported materials, were identified as the most up-to-date and recently used catalysts for the removal of NO gas. The main focus of this review is the study of catalyst preparation methods, as this is highly correlated to the behaviour of NO removal. The general mechanisms involved in the system, the Langmuir-Hinshelwood or Eley-Riedeal mechanism, are also discussed. Characterisation analysis affecting the surface and chemical structure of the catalyst is also detailed in this work. Finally, a few major conclusions are drawn and future directions for work on the advancement of the $\mathrm{SCR}-\mathrm{NH}_{3}$ catalyst are suggested.
\end{abstract}

\section{Review \\ Introduction}

Nowadays, air pollution has become a major environmental problem, which affects the natural characteristics of the atmosphere (gaseous constituents, water vapour that determines humidity and ozone layer) and adversely impacts the environment and human health. Nitrogen oxides $\left(\mathrm{NO}_{x}, x=1,2\right)$ are irritant gases that cause problems such as photochemical smog, formation of fine particles (PM), acid rain, ozone depletion, and the release of greenhouse gases to the environment [1]. NO is considered to be the most difficult gas to remove from the atmosphere because it behaves like a supercritical fluid at room temperature. On the other hand, $\mathrm{NO}_{2}$ can easily be removed because of its propensity to dissolve in water. Thus, the difficulty in $\mathrm{NO}$ elimination is the main challenge in $\mathrm{NO}_{x}$ gas removal. In fact, NO is the main pollutant, representing about 
$90 \%$ of total $\mathrm{NO}_{x}$ [2]. The main source of $\mathrm{NO}_{x}$ emissions is dominated by stationary sources, which originate from industrial processes, energy production and distribution, transportation, and agriculture. In large cities where motor vehicle traffic is high, a huge amount of $\mathrm{NO}_{x}$ is released into the environment. This phenomenon can significantly cause detriment to public health. To overcome this problem, maximum standards for $\mathrm{NO}_{x}$ emissions have been reinforced in the transportation sector. These guidelines and regulations must be adhered to and numerous efforts taken in order to reduce $\mathrm{NO}_{x}$ emissions in the atmosphere. However, more beneficial and economic ways to remove NO are still lacking and are yet to be practically evaluated.

In recent years, many abatement technologies including dry and wet techniques have been utilised in industrial boilers and power plants to control $\mathrm{NO}_{x}$ emissions. Post-combustion such as selective catalytic reduction (SCR), non-selective catalytic reduction (NSCR), adsorption, corona discharge, electrochemical cell, radiation, and the wet system are examples of the dry technique while the scrubber is an example of the wet technique [3]. Of these technologies, due to its effectiveness, low cost, and high selectivity, the SCR of NO has emerged as the most promising method and has been widely applied over several decades to meet the stringent regulation of NO emissions from stationary sources [4]. Meanwhile, the three-way catalyst with carbon monoxide ( $\mathrm{CO}$ ) and hydrocarbon is also used in mobile sources to remove NO from gasoline, but this technology is limited to diesel and lean-burn gasoline engines. In the SCR of NO, a reducing agent must be introduced into the system in order to successfully convert $\mathrm{NO}$ into nitrogen $\left(\mathrm{N}_{2}\right)$, inert gases such as ammonia $\left(\mathrm{NH}_{3}\right)$, and urea [5]. The reaction system reduces the Gibbs free energy values initiated by the reducing agent; the introduction of oxygen also contributes to this occurrence. According to results from the literature, $\mathrm{NH}_{3}$ is the most practical reducing agent in the SCR of NO, as it results in high NO removal. The catalyst plays an important role in enhancing NO-SCR technology. The most widely used catalyst is $\mathrm{V}_{2} \mathrm{O}_{5}-\mathrm{WO}_{3} / \mathrm{TiO}_{2}$ due to its excellent catalytic activity and its high resistance to sulphur poisoning [6]. However, some problems are still evident with the use of this catalyst, e.g., the vanadium species is highly toxic to humans and the environment, and excessive dust pollution will usually result from the upstream flue gas, which can cause the deactivation of the catalyst. In addition, the catalyst also has a limited temperature window $\left(300-400{ }^{\circ} \mathrm{C}\right)$ and poor thermal stability $[7,8]$. Hence, there is an urgent need to find other catalysts that can overcome these drawbacks and also have high resistance to water $\left(\mathrm{H}_{2} \mathrm{O}\right)$ and oxidation of $\mathrm{SO}_{2}$ to $\mathrm{SO}_{3}$, so that high activity and selectivity, high thermal stability, and a temperature lower than $300{ }^{\circ} \mathrm{C}$ can be achieved, thus increasing the lifetime of the cata- lyst. Lower-temperature SCR is foremost in importance to ensure the complete removal of NO. This is because of the wide temperature window of $150-500{ }^{\circ} \mathrm{C}$ in a diesel engine as well as the low energy consumption and economy of $\mathrm{NH}_{3}$-SCR [9].

In the literature, abundant catalysts at low temperature have been explored such as transitional metals $(\mathrm{Mn}, \mathrm{Cu}, \mathrm{Ce}, \mathrm{Fe}, \mathrm{Co}$, Mo) [10-13], novel metals (Pt, Pd) [14], and metal ionexchange zeolite catalysts [15]. The Mn-based catalyst is one of the most active metal oxide catalysts for high $\mathrm{N}_{2}$ selectivity at low temperature and is recognised by many researchers as a potential alternative for the common catalyst. Jin et al. [16] successfully used a Mn-based catalyst with the addition of Ce to improve the activity and stability of SCR performance. It is well known that $\mathrm{Ce}$ is a good additive that can provide enough oxygen groups with the ability to release or store oxygen, thus improving the catalytic activity of SCR. In addition, over the last few years, the use of carbon-based catalysts have been widely studied due to their high surface area, porosity, ability to regenerate and be reused, and good support properties [17]. Several metal oxides were impregnated with carbon-based materials such as carbon nanotubes (CNTs), activated carbon (AC), activated carbon nanofibres (ACNFs), and graphene (GR). It is highly favourable to use these carbon-based materials as a catalyst support in the SCR system, as they can provide sites for active metals and protect the metals from sintering. However, they are also significantly affected by $\mathrm{H}_{2} \mathrm{O}$ and $\mathrm{SO}_{2}$ poisoning.

There are various methods for preparing a catalyst such as impregnation, sol-gel, incipient-wetness, co-precipitation, electroplating, and the polyol process. Some of the catalysts prepared via these methods can achieve low temperatures of SCR with content resistance of $\mathrm{H}_{2} \mathrm{O}$ and $\mathrm{SO}_{2}$. Each method is different from the other, and thus each affects the structure and physical and chemical properties of the catalyst. In fact, choosing the best method for catalyst preparation is crucial in order to increase the interaction between the metal and support, and to obtain a desirable catalyst particle size. Lázaro et al. [17] summarised the carbon-based catalysts for SCR at low temperature and compared it with commercial catalysts. A good example can be seen in Chuang et al. [18], where a comparative study was made between the preparation of AC-supported $\mathrm{Cu}$ catalysts through impregnation, the polyol process, and microwave-heated polyol process using $\mathrm{Cu}\left(\mathrm{NO}_{3}\right) \cdot 3 \mathrm{H}_{2} \mathrm{O}$ as the copper precursor.

To date, many researchers have reviewed the SCR of NO at low temperature. Li et al. [9] reviewed low-temperature SCR on metal oxide and zeolite catalysts with a focus on catalyst performance and taking into account other possible mechanisms. 
Meanwhile, Mrad et al. [5] reviewed and summarised the use of a hydrocarbon catalyst in the SCR of NO. However, not much effort has been made to summarise the progress of catalyst synthesis methods to achieve catalytic activity at low-temperature SCR. Therefore, this paper addresses this gap by reviewing the development of catalyst preparation methods.

In this paper, the current progress in research on low-temperature SCR of NO over metal and bi-metallic oxides with carbonbased catalysts is reviewed. Furthermore, this review provides a comprehensive focus on the methods of catalyst preparation that can provide high activity, high stability, and convey good resistance towards $\mathrm{H}_{2} \mathrm{O}$ and $\mathrm{SO}_{2}$. The reaction mechanism for $\mathrm{NO}$ removal is also discussed. Finally, major conclusions and future directions for research on the SCR of NO are presented.

\section{Mechanism of NO removal}

The adsorption behaviour of gas on the catalyst surface is known to be an important factor for understanding the chemical nature of SCR. In $\mathrm{NH}_{3}$-SCR, $\mathrm{NO}$ is targeted and reduced to $\mathrm{N}_{2}$, which can then be safely released into the surroundings. The typical mechanism for the SCR- $\mathrm{NH}_{3}$ of $\mathrm{NO}$, which involves $\mathrm{O}_{2}$, is outlined in Equation 1 [19].

$$
4 \mathrm{NO}+\mathrm{O}_{2}+4 \mathrm{NH}_{3}=4 \mathrm{~N}_{2}+6 \mathrm{H}_{2} \mathrm{O}
$$

In the absence of $\mathrm{O}_{2}$, the reaction mechanism follows Equation 2.

$$
6 \mathrm{NO}+4 \mathrm{NH}_{3}=5 \mathrm{~N}_{2}+6 \mathrm{H}_{2} \mathrm{O}
$$

Equation 1 is recommended as the standard reaction for $\mathrm{NH}_{3}-$ SCR of NO, as more than $90 \%$ of NO is present among the $\mathrm{NO}_{x}$ species and thus controlling the reaction stoichiometry. In the standard SCR mechanism of Equation 1, one molecule of $\mathrm{NH}_{3}$ is required to reduce one molecule of $\mathrm{NO}$ with the excess $\mathrm{O}_{2}$.

However, fast SCR may also occur in the presence of $\mathrm{O}_{2}$ with $\mathrm{NO}$ and $\mathrm{NO}_{2}$ over active components. In the presence of $\mathrm{O}_{2}$, $\mathrm{NO}_{2}$ can be formed when $\mathrm{NO}$ is being oxidised by active oxygen. The general reactions are described by Equation 3 and Equation 4 [20].

$$
\begin{gathered}
2 \mathrm{NO}_{2}+\mathrm{O}_{2}+4 \mathrm{NH}_{3}=3 \mathrm{~N}_{2}+6 \mathrm{H}_{2} \mathrm{O} \\
2 \mathrm{NO}_{2}+2 \mathrm{NO}+4 \mathrm{NH}_{3}=4 \mathrm{~N}_{2}+6 \mathrm{H}_{2} \mathrm{O}
\end{gathered}
$$

Fast SCR and standard SCR can be distinguished according to the formation of $\mathrm{NO}_{2}$. In fast $\mathrm{SCR}$, nitrous acid $\left(\mathrm{HNO}_{2}\right)$ and nitric acid $\left(\mathrm{HNO}_{3}\right)$ are formed from the dimerisation of $\mathrm{NO}_{2}$ [2]. Then, an ammonium nitrate $\left(\mathrm{H}_{4} \mathrm{NNO}_{3}\right)$ intermediate is formed when $\mathrm{NH}_{3}$ reacts with $\mathrm{HNO}_{3}$ and subsequently decomposes to $\mathrm{N}_{2} \mathrm{O}$ and $\mathrm{H}_{2} \mathrm{O}$ by $\mathrm{NO}$ at higher temperature [20].

It is noted that $\mathrm{NO}_{2}$ is highly crucial in the fast $\mathrm{SCR}$ reaction, as $\mathrm{NO}_{2}$ is a more powerful oxidising agent compared to $\mathrm{O}_{2}$. Thus, the reaction between $\mathrm{NO}$ and $\mathrm{HNO}_{3}$ is significant in determining the rate-limiting step of fast SCR. According to Nova et al. [20], a ratio of $\mathrm{NO} / \mathrm{NH}_{3}$ approaching 1 is good for increasing the reaction rate, whereby the formation of $\mathrm{NO}_{2}$ will be inhibited when the $\mathrm{NH}_{3}$ concentration is increased, which restrains the formation of $\mathrm{HNO}_{3}$. Indeed, Nova et al. [20] also addressed the mechanism of fast $\mathrm{SCR}$ reaction over $\mathrm{V}_{2} \mathrm{O}_{5}-\mathrm{WO}_{3} / \mathrm{TiO}_{2}$ catalysts. They concluded that $\mathrm{NO}_{2}$ is vital for attaining faster reoxidation of the vanadium sites.

There are two surface reactions that are usually involved in the NO removal system: the Langmuir-Hinshelwood and Eley-Rideal mechanisms [9]. It is believed that $\mathrm{NH}_{3}$ is first adsorbed by both Lewis acid sites and Brønsted acid sites followed by $\mathrm{NO}$ and $\mathrm{O}_{2}$.

\section{Langmuir-Hinshelwood mechanism}

The Langmuir-Hinshelwood mechanism occurs when two molecules of $\mathrm{NO}$ and $\mathrm{NH}_{3}$ are adsorbed to the catalyst surface and then bonded together to form $\mathrm{N}_{2}$ and $\mathrm{H}_{2} \mathrm{O}$. Liu et al. [21] examined the Langmuir-Hinshelwood mechanism over a $\mathrm{MnO}_{x}$ $\mathrm{CeO}_{2}$ catalyst reaction. The adsorbed $\mathrm{NH}_{3}$ on the Lewis acid sites formed activated $\mathrm{NH}_{3}$, which is a $\mathrm{NH}_{2}{ }^{-}$ species, in the oxidation dehydrogenation process. The NO that was oxidised to $\mathrm{NO}_{2}$ on the catalyst surface reacted with $\mathrm{NH}_{2}{ }^{-}$ to produce intermediate nitrosamine $\left(\mathrm{NH}_{2} \mathrm{NO}\right)$. The proposed Langmuir-Hinshelwood reaction scheme is outlined by Equation 5-9.

$$
\begin{gathered}
\mathrm{NO}(\mathrm{g}) \rightarrow \mathrm{NO}(\mathrm{ad}) \\
\mathrm{NH}_{3}(\mathrm{~g}) \rightarrow \mathrm{NH}_{3}(\mathrm{ad}) \\
\mathrm{NH}_{3}^{-} *+\mathrm{O}^{-} * \rightarrow \mathrm{NH}_{2}^{-} *+\mathrm{OH}^{-} \\
\mathrm{NO}+1 / 2 \mathrm{O}_{2} \rightarrow \mathrm{NO}_{2}^{-} * \\
\mathrm{NH}_{2}^{-}{ }^{-}+\mathrm{NO} \rightarrow \mathrm{NH}_{2} \mathrm{NO}^{-} \rightarrow \mathrm{N}_{2}+\mathrm{H}_{2} \mathrm{O}+*
\end{gathered}
$$

where $*$ represents the Lewis acid sites on the catalyst surface.

Firstly, gaseous $\mathrm{NO}$ and $\mathrm{NH}_{3}$ are adsorbed on the catalyst surface, as per Equation 5 and Equation 6. As the reaction starts with $\mathrm{NH}_{3}, \mathrm{NH}_{3}$ will be adsorbed on the Lewis acid sites and Brønsted acid sites and then oxidised into coordinated $\mathrm{NH}_{3}$ species and ionic $\mathrm{NH}_{4}{ }^{+}$, while $\mathrm{NO}$ is oxidised into $\mathrm{NO}_{2}$ via 
Equation 7 and Equation 8, respectively. The manganese and ceria cations used in this reaction contribute to the large amount of Lewis acid sites. It is noted that the $\mathrm{NH}_{4}{ }^{+}$formed on the Brønsted acid sites are not necessary in the SCR reaction at low temperature. Furthermore, the oxidised NO reacts with adjacent activated $\mathrm{NH}_{3}$ species to form intermediate $\mathrm{NH}_{2} \mathrm{NO}^{-}$. After that, it will decompose into $\mathrm{N}_{2}$ and $\mathrm{H}_{2} \mathrm{O}$, as per Equation 9.

\section{Eley-Rideal mechanism}

The Eley-Rideal mechanism suggests that only one molecule will adsorb on the catalyst surface and the second molecule will react with it directly from the gas phase (van der Waals force) to form a new product. Liu et al. [22] found that the $\mathrm{Fe}_{2} \mathrm{O}_{3}$ catalyst forms amide species $\left(\mathrm{NH}_{2}^{-}\right)$in the presence of $\mathrm{NH}_{3}$ on the Lewis acid sites and reacted directly with gaseous NO to form $\mathrm{N}_{2}$ and $\mathrm{H}_{2} \mathrm{O}$, as per Equation 10-12, respectively:

$$
\begin{gathered}
\mathrm{NH}_{3}(\mathrm{~g}) \rightarrow \mathrm{NH}_{3}(\mathrm{ad}) \\
\mathrm{NH}_{3}+* \rightarrow \mathrm{NH}_{2}{ }^{-}+\mathrm{H} \\
\mathrm{NH}_{2}{ }^{-}+\mathrm{NO} \rightarrow \mathrm{N}_{2}+\mathrm{H}_{2} \mathrm{O}
\end{gathered}
$$

In addition, Cha et al. [19] also proposed the Eley-Rideal mechanism involving $\mathrm{CeO}_{2}$. The higher quantity of $\mathrm{Ce}^{3+}$ ions over the $\mathrm{Ce}^{4+}$ ions facilitated the oxidation of $\mathrm{NH}_{3}$ to $\mathrm{N}_{2}$ and $\mathrm{H}_{2} \mathrm{O}$ for NO reduction in the SCR reaction. High $\mathrm{Ce}^{3+}$ ion concentration contributed to the high amount of chemisorbed oxygen, which increased the redox cycle and enhanced the reducibility of hydrogen. This is because the $\mathrm{Ce}^{3+}$ ions will assist the migration of $\mathrm{O}_{2}$ from gas phase to the surface of the catalyst $[8,23]$. Afterwards, Wei et al. [24] explained that $\mathrm{NO}_{x}$ removal using $\mathrm{FeCu}$ /zeolite catalyst followed both Eley-Rideal and Langmuir-Hinshelwood mechanisms. First, $\mathrm{NO}_{x}$ directly reacted with oxidised $\mathrm{NH}_{3}$ to express the Eley-Rideal mechanism, and the $\mathrm{NO}$ species reacted with $\mathrm{NH}_{3}$ species adsorbed to the $\mathrm{Fe}^{2+}$ and $\mathrm{Cu}^{2+}$ ions, following the Langmuir-Hinshelwood mechanism. Shi et al. [25] used DRIFT to investigate the chemical reaction of reactants with the Lewis acid site and Brønsted acid site to improve activity at low temperature. Chen et al. [26] found that $\mathrm{CeO}_{2}$ provided both acid sites, while $\mathrm{WO}_{3}$ helped in increasing the Brønsted acid sites in the $\mathrm{CeO}_{2}-\mathrm{WO}_{3}$ mixed oxide catalyst.

Generally, chemical reactions that occurr in the NO adsorption system involve a redox reaction on the surface of the catalyst and adsorption of $\mathrm{NO}, \mathrm{NH}_{3}$, and $\mathrm{O}_{2}$. The rate of a chemical reaction normally depends on the catalyst, which speeds up the reaction with less energy being required. Thus, the addition of a support for the catalyst will only increase the rate of reaction for NO removal. A redox reaction is a chemical reaction that involves the simultaneous occurrence of the oxidation and reduction process. This reaction occurs during the preparation of the catalyst between the active components and selected support. According to Liu et al. [27], the electronic inductive interaction between $\mathrm{Fe}^{3+}$ (metal) and $\mathrm{Ti}^{4+}$ (support) species will increase the oxidation ability of $\mathrm{Fe}^{3+}$ to $\mathrm{Fe}^{2+}$ species, which will then lead to the enhancement of surface active sites to readily react with NO. The synergetic effect of the metal cations present is important to increase the catalytic activity in the SCR of NO.

\section{Catalyst preparation}

The success of nitric oxide removal in a SCR reaction depends entirely on catalyst stability and activity [28]. The synthesis method is one of the key factors that contribute towards an even distribution of the active component and good particle properties [29]. Different preparation methods have been carried out by modifying the current SCR catalyst to achieve high NO selectivity in the $\mathrm{NH}_{3}$-SCR system. Impregnation is one of the most commonly used techniques due to its simplicity [30]. This method starts with the inclusion of metals $(\mathrm{Zn}, \mathrm{Cu}, \mathrm{Ni}, \mathrm{Co}, \mathrm{Fe}$ or $\mathrm{Mn}$ ) into the catalyst support material. A metal solution precursor is commonly added together with the support material. After mixing, the surface material is allowed to fully submerge with the selection of metals through continuous mixing. Sonication or stirring methods are applied to assure the upmost dispersion of metal in the solution precursor [31]. In the end, the precursor supported material is dried followed by consecutive heat treatment with inert gas in order to further enhance and stabilise the metal catalyst [32]. Owing to its ease of metal loading control as well as high utilisation of the active component with less metal precursor dosage, the impregnation method is profoundly known as one of the well established procedures for SCR catalyst preparation [32,33]. Jeong et al. [34] applied the impregnation technique to study the characteristics of graphenesupported tungsten $\left(\mathrm{WO}_{3}\right)$ catalyst in a selective catalytic reduction system. The transmission electron microscopy energydispersive X-ray spectroscopy (TEM-EDS) measurements in their study showed that the $\mathrm{WO}_{3}$ particles were very well distributed over GR and the catalyst surface. The use of a precursor solution (ammonium metatungstate) further enhanced the dispersion of GR, resulting in high catalyst dispersion. Thus, huge amounts of NO could be successfully removed via the catalytic reaction. Qi et al. [35] used the impregnation method to prepare Ce-modified Mn-based catalysts with the aim of studying the effect of a different calcination atmosphere $\left(\mathrm{N}_{2}\right.$, air and $\mathrm{O}_{2}$ ) on the performance of SCR-NH $\mathrm{N}_{3}$ of NO. Both Ce and $\mathrm{Mn}$ particles were well distributed onto the catalyst surface. Nam et al. [36] proposed an impregnation method to investigate the promotional effects of tungsten-modified $\mathrm{Mn} / \mathrm{Ce} / \mathrm{Ti}$ catalysts for a low-temperature SCR reaction. It was found that 
introduction of $\mathrm{W}$ metal into the catalyst helped promote the conversion of $\mathrm{NO}$ to gaseous $\mathrm{NO}_{2}$, thereby promoting a "fast SCR" reaction to improve low-temperature SCR activity.

The sol-gel method has been used quite frequently for the development of nano-based catalysts. Basically, certain chemical solutions together with a foaming agent (citric acid) is mixed vigorously by stirring under room temperature to produce a homogeneous mixture. Subsequently, the produced sols are dried at a specific temperature for 24 hours in order to obtain xerogel. Then, the xerogel is crushed before being calcined at a desired atmosphere condition and temperature [37]. In the case of catalyst preparation, many researchers have adopted the sol-gel method because: (i) it can form a more even distribution of metal component onto the support material, (ii) it can alter the catalyst porous structure using various foaming agents, (iii) it is able to synthesise the metal-supported catalyst in a single-step process, leading to a unique metal oxide interaction and oxide-oxide interactions that are unreachable otherwise [38] Xiong et al. [39] prepared magnetic iron-cerium-tungsten mixed oxide pellets using a citric acid sol-gel process assisted by microwave irradiation for the SCR-NH $\mathrm{N}_{3}$ of NO. They found that the dispersion of both cerium oxide and tungsten oxide onto iron the oxide was improved. In addition, the surface absorbtion capacity of oxygen concentration was enhanced, thus increasing selective catalytic reduction activity. Yao et al. [40] investigated certain physiochemical properties and found that $\mathrm{SCR}-\mathrm{NH}_{3}$ catalytic performance is influenced by the function of support materials. In their study, $\mathrm{SiO}_{2}$ was synthesised using the sol-gel method. Zeng et al. [41] implemented the sol-gel technique to prepare $\mathrm{CuO}-\mathrm{TiO}_{2}$ catalysts for the selective catalytic oxidation of $\mathrm{NO}$. Based on the results, the $\mathrm{CuO}-\mathrm{TiO}_{2}$ catalysts demonstrated higher catalytic activity than the $\mathrm{Cu}_{0.07} / \mathrm{Ti}$ catalyst prepared using the impregnation method. The $\mathrm{CuO}-\mathrm{TiO}_{2}$ catalyst possessed more highly dispersed $\mathrm{CuO}$ species as well as many oxygen vacancy active sites, which enhanced the NO gas and made it easily attachable during the catalytic reaction. Similar to previous work, Zhu et al. [42] applied the sol-gel method to study the effect of a particular synthesis method on the catalytic activities of $\mathrm{CoO}_{x}-\mathrm{TiO}_{2}$ at low-temperature SCR$\mathrm{NH}_{3}$. In comparison, the $\mathrm{CoO}_{x}-\mathrm{TiO}_{2}$ catalyst was also prepared using the impregnation approach. They found that the $\mathrm{Co}-\mathrm{TiO}_{2}$ catalyst prepared using the sol-gel method had better catalytic activity than that of the impregnation method. Besides that, a huge amount of oxygen vacancies and superoxide ions was observed when cobalt metal was introduced via the sol-gel method, thereby enhancing the SCR performance.

On the other hand, the co-precipitation method has also been applied in the preparation of the SCR catalyst. This technique is much more preferable due to its simple handling procedure and time-saving process. In addition, particle size and composition of the catalyst structure is easy to control [43]. In general, the preparation method starts by initially dissolving a certain amount of metal chemical forms into a homogenous solution. An ammonia solution is then added gradually to the earlier mixture until the $\mathrm{pH}$ reaches 10 . Then, the slurry is filtered, washed, and dried overnight in the oven before undergoing the activation procedure in the furnace at a specified reaction temperature. Many researchers have used the co-precipitation technique for catalyst preparation to investigate the SCR reaction of NO. For instance, Zhang et al. [44] prepared $\mathrm{Mn}-\mathrm{FeO}_{x} / \mathrm{CNT}$ catalysts through redox co-precipitation to investigate $\mathrm{NO}$ reduction with $\mathrm{NH}_{3}$ at low operating temperatures. Excellent SCR activity was observed since the $\mathrm{Mn}-\mathrm{FeO}_{x} / \mathrm{CNT}$ catalysts possessed high-stability morphology, high chemisorbed oxygen content, as well as strong reducibility at low SCR temperature. Zhang et al. [45] used the co-precipitation method to produce a high loading $\mathrm{Zn}$ - (Fe-, Ni-, $\mathrm{Cu}$ - or $\mathrm{Ag}$-) promoted $\mathrm{Co} / \mathrm{Al}_{2} \mathrm{O}_{3}$ catalyst to study the effect of additive metals on the SCR of NO. From the experimental studies, it was found that this technique definitely contributes towards a good homogeneous dispersion and helps prevent aggregation of highly deposited cobalt on alumina. Moreover, a uniform morphology of the catalyst was obtained and small-sized deposited cobalt was sustained under the presence of $\mathrm{Fe}, \mathrm{Ni}, \mathrm{Cu}, \mathrm{Zn}$ or Ag. Meanwhile, Sun et al. [46] planned to enhance the performance of $\mathrm{MnO}_{x}$ catalyst for the $\mathrm{SCR}-\mathrm{NH}_{3}$ of $\mathrm{NO}$ reaction by modifying it with Eu using the co-precipitation method. An enhanced performance of the $\mathrm{MnO}_{x}$ catalyst was observed due to the strong interaction between $\mathrm{Mn}$ and $\mathrm{Eu}$, which hinders the $\mathrm{MnO}_{x}$ crystallisation process.

Overall, there are various types of synthesis methods (impregnation, sol-gel, co-precipitation, incipient wetness, and pyridine thermal) that can be used to prepare the SCR catalyst for NO removal. Some of the previously mentioned preparation methods are among the most commonly applied techniques for the SCR-NH 3 of NO. However, traditional catalyst preparation methods (such as impregnation and co-precipitation) usually result in poor dispersion of the active component and pore blocking on the catalyst surface, thereby decreasing the removal activity of NO $[32,47]$. Hence, the sol-gel method is seen as the best method for catalyst preparation since it helps achieve better physiochemical properties of SCR catalysts [48].

\section{Typical characterisation techniques for catalysts}

The importance of the characterisation of catalysts for the SCR$\mathrm{NH}_{3}$ reaction for the removal of nitric oxide can be linked specifically to the inner structure of the catalyst. The characteristic features are highly associated with the deposition of car- 
bon onto the catalyst surface, changes of phase, behavior of the catalyst support and active sites, catalyst morphology, type of carbon present on the catalyst, as well as the catalyst chemistry. A broad mixture of characterisation techniques have been applied to characterise the SCR- $\mathrm{NH}_{3}$ catalyst, as summarized in the the following [49].

In particular, the catalyst active phases before and after SCR$\mathrm{NH}_{3}$ reaction are typically characterised by:

- atomic absorption spectroscopy (AAS)

- X-ray fluorescence spectroscopy (XRF)

- electron paramagnetic resonance (EPR)

- X-ray photoelectron spectroscopy (XPS)

- temperature-programmed reduction (TPR)

- X-ray diffraction (XRD)

The dispersion of metal, particle size of the catalyst and original state of the metal on the $\mathrm{SCR}-\mathrm{NH}_{3}$ supported catalysts can be characterised by the following techniques:

- transmission electron microscopy (TEM)

- scanning electron microscopy (SEM)

- X-ray diffraction (XRD)

- $\mathrm{CO}$ chemisorption

The behaviour of the $\mathrm{SCR}-\mathrm{NH}_{3}$ catalyst deposition is typically characterised by:

- temperature-programmed surface reaction (TPSR)

- mass spectroscopy (MS)

- differential thermal analysis (DTA)

- thermogravimetric analysis (TGA)

- temperature-programmed hydrogenation (TPH)

- temperature-programmed oxidation (TPO)

Table 1 summarises the typical characterisation approach for SCR-NH $\mathrm{N}_{3}$ catalysts.

\section{Carbon-based materials as catalyst supports for NO removal}

Carbonious materials have rich physical and chemical properties, which lend to their high porosity and good surface chemistry. In line with this, carbon-based materials are found suitable for use in most catalytic process applications. Although carbonious materials have traditionally been used as supports for catalysts in heterogeneous catalytic processes, they are becoming more familiar as catalysts of their own [63-65]. Carbon nanotubes (CNTs), activated carbon (AC), and graphene (GR) are among the most typical choices for carbon-based supports.
Several features can be seen when applying carbon-based materials as a catalyst support. The dispersion of the active phase over the support increases due to the large surface area and high porosity $[64,66]$. The pore size distribution can be altered to suit the requirements of a specific type of reaction. The surface chemistry of a carbon-based catalyst also plays a significant role, as it influences catalytic performance especially during the synthesis stage. In terms of interactions, carbon-based materials are known to be hydrophobic in nature. These materials normally show a low affinity against polar solvents, such as water, and in other cases, have a high affinity against non-polar solvents, such as acetone. Although the essence of carbon-based materials are mostly likely to be hydrophobic, which will eventually agitate the uniform distribution of the active component onto the carbon support, the surface chemistry of the carbon material could be simply adjusted, for instance, by undergoing an oxidation process, in order to increase the hydrophilicity of the carbon materials. Aside from the easy modification of the porous structure and surface chemistry, carbon-based materials also portray other distinct advantages [64]: (i) easier reduction of metals on the support; (ii) resistance towards acids and bases resulting in best carbon structure; (iii) firm at high working temperature $\left(>750{ }^{\circ} \mathrm{C}\right)$ due to sturdy carbon composition; (iv) able to be produced in different physical shape (granules, pellets, fibres, and cloth) as carbon-based catalyst is very much porous in structure; (v) the cost of carbon-based supports is usually lower and more economical as compared to the conventional supports (silica and alumina) [67].

In recent years, many industrial applications have used carbon as a support material for catalysts. These catalysts are applied during the reaction process of oxidising organic compounds, desulphurisation, halogenation, and as fuel cells [64,66,67]. Unfortunately, all these industrial processes result in an unhealthy environment. Nowadays, treating the emission of nitric oxide, especially from industrial exhaust gas, has become a great concern $[54,68-70]$.

Various types of metal species have been incorporated onto the surface of carbon materials. In order to integrate carbon materials with metal or metal oxide, a functionalisation process known as pre-treatment is required since the surface of pristine CNTs is hydrophobic and inert in nature. Unfortunately, existing preparation methods suffer from scarce deposition, catalyst particle aggregation, and unwanted large-sized metal particles. After attaching the oxide functional group onto the CNTs, the main properties of CNTs are usually affected. As a result, the performance of the as-prepared hybrid material will be impaired. Therefore, more preparation methods with less impact on the properties of CNTs have to be developed. This process is also important for the purification of pristine CNTs from amor- 


\begin{tabular}{|c|c|c|c|}
\hline Characterisation techniques & Catalyst & Aspects characterised or investigated & Refs. \\
\hline XRD \& TEM & $\begin{array}{l}\text { Mn/CNT } \\
\text { Mn/ZSM-5 }\end{array}$ & average size of active particles on the catalyst surface & {$[50,51]$} \\
\hline $\mathrm{NH}_{3}$-TPD & $\begin{array}{l}\mathrm{CuO} / \mathrm{CNT} \\
\mathrm{CeO}_{2} / \mathrm{CNT}\end{array}$ & adsorption state of $\mathrm{NH}_{3}$ on the surface of the catalyst & {$[52,53]$} \\
\hline TPD & $\mathrm{V}_{2} \mathrm{O}_{5} / \mathrm{CNT}$ & effect of different catalysts surface on $\mathrm{SO}_{2}$ adsorption & {$[54]$} \\
\hline $\mathrm{H}_{2}$-TPR & $\begin{array}{l}\mathrm{Mn} / \mathrm{CNT} \\
\mathrm{Mn} / \mathrm{ZSM}-5 \\
\mathrm{CeO}_{2} / \mathrm{CNT} \\
\mathrm{MnO}_{x} / \mathrm{CNT} \\
\mathrm{Fe}-\mathrm{Cu}-\mathrm{O}_{x} / \mathrm{CNT}-\mathrm{TiO}_{2} \\
\mathrm{CuCe} / \mathrm{ZSM}-5 \\
\mathrm{CeMo} \mathrm{O}_{y} / \mathrm{Al}_{2} \mathrm{O}_{3}\end{array}$ & reducibility of the catalysts & $\begin{array}{l}{[50,51,} \\
53,55- \\
60]\end{array}$ \\
\hline TGA & $\begin{array}{l}\mathrm{Mn}-\mathrm{Ce} / \mathrm{CNT} \\
\mathrm{MnO}_{x} / \mathrm{CNT}\end{array}$ & thermal stability & $\begin{array}{l}{[55]} \\
{[57]}\end{array}$ \\
\hline XPS & $\begin{array}{l}\mathrm{Mn} / \mathrm{CNT} \\
\mathrm{Mn} / \mathrm{ZSM}-5 \\
\mathrm{CeO}_{2} / \mathrm{CNT}\end{array}$ & surface chemical states and amount of the active component & $\begin{array}{l}{[50,51} \\
53]\end{array}$ \\
\hline Raman & $\mathrm{Mn} / \mathrm{CNT}$ & $\begin{array}{l}\text { interaction between confined metal species and support } \\
\text { material }\end{array}$ & {$[50]$} \\
\hline NO-TPD \& DRIFT spectra & $\mathrm{Mn} / \mathrm{CNT}$ & interaction of NO with the surface of the catalysts & {$[50]$} \\
\hline $\mathrm{XRD}$ & $\begin{array}{l}\mathrm{Fe}-\mathrm{Cu}-\mathrm{O}_{x} / \mathrm{CNT}-\mathrm{TiO}_{2} \\
\mathrm{~V}_{2} \mathrm{O}_{5}-\mathrm{WO}_{3} / \mathrm{CNT} \\
\mathrm{Mn}-\mathrm{Ce} / \mathrm{CNT} \\
\mathrm{MnO}_{x} / \mathrm{TiO}_{2}\end{array}$ & crystalline phase and structure of catalyst & $\begin{array}{l}{[47,56} \\
57,61]\end{array}$ \\
\hline SEM & $\begin{array}{l}\mathrm{Fe}-\mathrm{Cu}-\mathrm{O}_{x} / \mathrm{CNT}-\mathrm{TiO}_{2} \\
\mathrm{~V}_{2} \mathrm{O}_{5}-\mathrm{WO}_{3} / \mathrm{CNT}\end{array}$ & characterise the morphologies of the samples & {$[56,61]$} \\
\hline XPS & $\begin{array}{l}\mathrm{Fe}-\mathrm{Cu}-\mathrm{O}_{x} / \mathrm{CNT}-\mathrm{TiO}_{2} \\
\mathrm{Mn}-\mathrm{Ce} / \mathrm{CNT} \\
\mathrm{Ce}-\mathrm{MnO}_{x} / \mathrm{TiO}_{2} \\
\mathrm{M}_{x} \mathrm{O}_{y}-\mathrm{V}_{2} \mathrm{O}_{5}-\mathrm{WO}_{3} / \mathrm{TiO}_{2} \\
\mathrm{CeMo} \mathrm{O}_{x} \mathrm{O}_{y} / \mathrm{Al}_{2} \mathrm{O}_{3}\end{array}$ & peak intensity of active metal & [56-60] \\
\hline $\mathrm{NH}_{3}$-TPD & $\begin{array}{l}\mathrm{Fe}-\mathrm{Cu}-\mathrm{O}_{x} / \mathrm{CNT}-\mathrm{TiO}_{2} \\
\mathrm{~V}_{2} \mathrm{O}_{5}-\mathrm{WO}_{3} / \mathrm{CNT} \\
\mathrm{M}_{x} \mathrm{O}_{y}-\mathrm{V}_{2} \mathrm{O}_{5}-\mathrm{WO}_{3} / \mathrm{TiO}_{2} \\
\mathrm{Ce}-\mathrm{MnO}_{x} / \mathrm{TiO}_{2} \\
\mathrm{CuCe} / \mathrm{ZSM}-5\end{array}$ & acidic sites in the catalyst & $\begin{array}{l}{[56,58,} \\
59,61, \\
62]\end{array}$ \\
\hline NOx-TPD & $\mathrm{Fe}-\mathrm{Cu}-\mathrm{O}_{x} / \mathrm{CNT}-\mathrm{TiO}_{2}$ & record the $\mathrm{NO}$ and $\mathrm{NO}_{2}$ signals & {$[56]$} \\
\hline TEM & $\begin{array}{l}\mathrm{Fe}-\mathrm{Cu}-\mathrm{O}_{x} / \mathrm{CNT}-\mathrm{TiO}_{2} \\
\mathrm{~V}_{2} \mathrm{O}_{5}-\mathrm{WO}_{3} / \mathrm{CNT} \\
\mathrm{Mn}-\mathrm{Ce} / \mathrm{CNT} \\
\mathrm{CuCe} / \mathrm{ZSM}-5\end{array}$ & support diameter and metal species particle size & $\begin{array}{l}{[56,57,} \\
61,62]\end{array}$ \\
\hline BET & $\begin{array}{l}\mathrm{Mn} / \mathrm{ZSM}-5 \\
\mathrm{Mn}-\mathrm{Ce} / \mathrm{CNT} \\
\mathrm{Ce}-\mathrm{MnO}_{x} / \mathrm{TiO}_{2} \\
\mathrm{MnO}_{x} / \mathrm{TiO}_{2} \\
\mathrm{M}_{x} \mathrm{O}_{y}-\mathrm{V}_{2} \mathrm{O}_{5}-\mathrm{WO}_{3} / \mathrm{TiO}_{2}\end{array}$ & $\begin{array}{l}\text { textural properties of the catalyst (specific surface area, pore } \\
\text { volume, and pore size of catalysts) }\end{array}$ & $\begin{array}{l}{[47,51} \\
57-59]\end{array}$ \\
\hline TPR & $\mathrm{Ce}-\mathrm{MnO}_{x} / \mathrm{TiO}_{2}$ & influence of metal content on the oxidation states of catalyst & {$[58]$} \\
\hline XRD & $\mathrm{M}_{x} \mathrm{O}_{y}-\mathrm{V}_{2} \mathrm{O}_{5}-\mathrm{WO}_{3} / \mathrm{TiO}_{2}$ & crystalline phases of the supports and catalysts & {$[59]$} \\
\hline SEM \& TEM & $\mathrm{M}_{x} \mathrm{O}_{y}-\mathrm{V}_{2} \mathrm{O}_{5}-\mathrm{WO}_{3} / \mathrm{TiO}_{2}$ & morphologies and textural features of the catalyst & {$[59]$} \\
\hline
\end{tabular}

phous carbon, fullerenes, coal, and catalyst particles by means of their production. The wet chemical method is considered to be one of the most efficient methods for purification, activation, and functionalisation of CNTs. In this method, CNTs are immersed in a solution containing an oxidising agent for a few hours. A certain amount of heat is also applied to accelerate the oxidation process. The most commonly used technique for sur- face oxidation is acid treatment such as nitric acid or preferably nitric/sulphuric acid, as this results in the formation of oxygencontaining groups $(\mathrm{OH}, \mathrm{C}=\mathrm{O}$ and $\mathrm{COOH})$ on the surface of the CNTs. The amount of oxygen-containing groups formed depends on the treatment method used. The chemical modification of the surface of (MWCNTs) multiwall carbon nanotubes is required via the oxygenated functional groups for the attach- 
ment of metal nanoparticles. It is believed that the oxidative treatment may create defects to the hexagonal or pentagonal structures of the GR sheet in the nanotubes. The functional groups can be introduced at the bent parts, defect sites, and at the sidewall of the MWCNTs. Acid treatment enables the covalent attachment of oxygenated groups on the surface and the open ends of the CNTs. After undergoing pre-treatment, the treated-CNTs will be dispersed with the choice of metal species. In the next step, several synthesis methods are applied such as impregnation, pyridine thermal, sol-gel, and incipient wetness in order to enhance the dispersion of metal element onto the carbon surface. Therefore, a proper preparation technique for the carbon-based catalyst is important to obtain good catalytic performance.

\section{Carbon nanotubes as a catalyst support}

Nowadays, CNTs are recognised as an attractive catalyst support for SCR catalysts due to their electronic properties and unique nanostructure [71-73]. CNT-supported metal oxide catalysts are well-known in the adsorption field and present interesting properties for the denitrification of $\mathrm{NO}_{x}$ species [74,75]. Ma et al. [56] investigated the $\mathrm{NO}$ activity at low operating temperatures on iron-copper-oxide $\mathrm{TiO}_{2}$ and $\mathrm{CNT}\left(\mathrm{Fe}-\mathrm{Cu}-\mathrm{O}_{x} / \mathrm{CNT}\right.$ $\mathrm{TiO}_{2}$ ) catalyst supports prepared via the sol-gel method. The $\mathrm{Fe}-\mathrm{Cu}-\mathrm{O}_{x} / \mathrm{CNT}-\mathrm{TiO}_{2}$ catalyst demonstrates the highest (90\%) nitric oxide conversion at a reaction temperature of 175 to $275{ }^{\circ} \mathrm{C}$. It is observed that the active component was highly dispersed onto the $\mathrm{TiO}_{2}$ and CNT surface because the copper oxide was not detectable by XRD measurements. CNTs play a significant role in the catalyst structure, as they promote the distribution of metal oxides. The XPS analysis shows that the intensity peak of $\mathrm{Cu}$ and $\mathrm{Fe}$ reduces when the CNTs are added into the catalyst, thus enhancing the conversion of nitric oxide. Moreover, $\mathrm{Fe}-\mathrm{Cu}-\mathrm{O}_{x} / \mathrm{CNT}-\mathrm{TiO}_{2}$ catalysts show high resistance towards $\mathrm{H}_{2} \mathrm{O}$ and $\mathrm{SO}_{2}$. With the introduction of $10 \% \mathrm{H}_{2} \mathrm{O}$ into the inlet gas at $225{ }^{\circ} \mathrm{C}$, the $\mathrm{NO}_{x}$ conversion rapidly decreased from $99 \%$ to $65 \%$ over the $\mathrm{Cu}_{3} \mathrm{Fe}_{1} \mathrm{Ti}_{85} \mathrm{C}_{5}$ catalyst, and then slowly recovered and kept constant at $85 \%$. On the contrary, the activity of $\mathrm{NO}_{x}$ completely recovered and remained consistent during 6 hours of testing, as soon as the $\mathrm{H}_{2} \mathrm{O}$ flow stopped. It was found that the competitive adsorption between the $\mathrm{H}_{2} \mathrm{O}$ molecule and $\mathrm{NH}_{3}$ reactant is the cause of reduction in the conversion of $\mathrm{NO}_{x}$ [76]. Meanwhile, the $\mathrm{NO}_{x}$ conversion immediately reduced from $99 \%$ to $84 \%$ when $\mathrm{SO}_{2}$ was present in the inlet gas at $225{ }^{\circ} \mathrm{C}$. Even after the $\mathrm{SO}_{2}$ introduction had stopped, the efficiency was still kept low (70\%), implying the phenomenon of catalyst deactivation. At $250{ }^{\circ} \mathrm{C}$ reaction temperature, $\mathrm{NO}_{x}$ removal also decreased to $81-84 \%$. However, when the $\mathrm{SO}_{2}$ supply was switched off, the $\mathrm{NO}_{x}$ recovered up to $88.34 \%$, suggesting a partial recovery of the catalyst deactivation. Phil et al. [77] and Li et al. [78] justified the possible reasons for catalyst deactivation. According to them, this was mostly due to the deposition of sulphates and bisulphates on the catalyst surface. By applying activated carbon (AC) as the catalyst support, the decomposition temperature of these species was reduced [79]. Correspondingly, in the study, the decomposition temperature of both sulphates and bisulphates were reduced with the introduction of CNTs as the support material for the catalyst. Hence, recovery of $\mathrm{SO}_{2}$ deactivation was achieved at $250{ }^{\circ} \mathrm{C}$.

Fang et al. [53] found that $\mathrm{CeO}_{2}$ particles are highly dispersed on the surface of CNTs when prepared using the pyridine-thermal (PT) route compared to other methods such as impregnation (IM) and physical mixture (PM). The $\mathrm{CeO}_{2} / \mathrm{CNT}-\mathrm{PT}$ has smaller and narrower ceria particle size distribution (2 to $14 \mathrm{~nm}$ ) than $\mathrm{CeO}_{2} / \mathrm{CNT}$-IM ( 6 to $20 \mathrm{~nm}$ ) based on the TEM and HRTEM analysis. In addition, $\mathrm{NH}_{3}$-TPD analysis was carried out in order to determine the surface acid amount and strength in the prepared catalysts. It was found that $\mathrm{CeO}_{2} / \mathrm{CNT}$-PT had much stronger acid sites since the desorption peaks shifted to a higher temperature range, as compared to $\mathrm{CeO}_{2} / \mathrm{CNT}$-IM and $\mathrm{CeO}_{2} / \mathrm{CNT}-\mathrm{PM}$ catalysts [80]. In this moment, the largest area of the desorption peaks can be observed in $\mathrm{CeO}_{2} / \mathrm{CNT}$-PT, signifying that the amount of $\mathrm{NH}_{3}$ adsorbed on the surface of $\mathrm{CeO}_{2}$ /CNT-PT is greater than on $\mathrm{CeO}_{2} / \mathrm{CNT}-\mathrm{IM}$ and $\mathrm{CeO}_{2} /$ CNT-PM [80,81]. Meanwhile, the XPS analysis indicates that there was more oxygen surface vacancy in the $\mathrm{CeO}_{2} / \mathrm{CNT}-\mathrm{PT}$ catalyst, thus, enhancing the $\mathrm{NH}_{3}-\mathrm{SCR}$ reaction. In comparison, Fang et al. [53] studied the performance of the catalysts via the impregnation and physical mixture methods. More than $90 \%$ of $\mathrm{NO}$ was removed at a reaction temperature between $250{ }^{\circ} \mathrm{C}$ and $370{ }^{\circ} \mathrm{C}$ for the $\mathrm{CeO}_{2} / \mathrm{CNT}$-PT catalyst compared to $\mathrm{CeO}_{2} / \mathrm{CNT}$ IM and $\mathrm{CeO}_{2} / \mathrm{CNT}$-PM with only $85 \%$ and $80 \%$ of NO conversion at a reaction temperature below $380{ }^{\circ} \mathrm{C}$, respectively. This suggests that the $\mathrm{CeO}_{2} / \mathrm{CNT}$-PT catalyst has better catalytic activity.

Wang et al. [57] investigated the use of mixed Mn-Ce oxidessupported CNTs (Mn-Ce/CNT) for NO removal. An array of $\mathrm{Mn}-\mathrm{Ce} / \mathrm{CNT}$ catalysts with different molar ratios (0.6 to $1.8 \%$ ) were prepared via the incipient-wetness method. During the preparation of the catalysts, the CNTs were pre-treated with concentrated nitric acid for roughly 16 hours. This procedure is advantegous since it helps with the dispersion of mixed oxides onto the surface of CNTs. More than $90 \%$ conversion of NO at a reaction temperature between $120^{\circ} \mathrm{C}$ to $180{ }^{\circ} \mathrm{C}$ was recorded by all $\mathrm{Mn}(0.4)-\mathrm{Ce} / \mathrm{CNT}$ catalysts. Diffraction peaks corresponding to CNTs were the only pattern detected by XRD for all $\mathrm{Mn}(0.4)-\mathrm{Ce} / \mathrm{CNT}$ catalysts. Beside that, negative peaks were observed in the $\mathrm{CeO}_{2}$ and $\mathrm{MnO}_{2}$ crystalline phase at high loading (1.8\%). This suggests that the Mn-Ce particles were 
evenly distributed on the CNTs. The TEM images specified that the size of Mn-Ce particles were very small crystals and well dispersed on the surface of the MWCNTs. Further analysis was conducted using HRTEM in order to determine the exact sizes and distribution of metal particles. The mixed metal was well distributed with Mn-Ce particle sizes ranging from 2 to $4 \mathrm{~nm}$ on the CNT surface. Su et al. [82] investigated the effect of the position of $\mathrm{MnO}_{x}$ particles inside and outside of CNT cavities on the NO activity in the SCR reaction. It is found that the $\mathrm{MnO}_{x}$ particles inside the CNTs displayed higher NO activity in the SCR reaction compared to when the $\mathrm{MnO}_{x}$ particles were introduced outside of the CNT surface. In line with this research, Wang et al. [57] found that the high catalytic performance by $\mathrm{Mn}-\mathrm{Ce} / \mathrm{CNT}$ catalyst was partly attributed to the $\mathrm{Mn}-\mathrm{Ce}$ particles found inside the cavity of the CNTs.

Wang et al. [83] reported high NO conversion $(\approx 90 \%)$ at a relatively high reaction temperature of 200 to $300{ }^{\circ} \mathrm{C}$ on the $\mathrm{Mn}-\mathrm{Ce} / \mathrm{CNT}$ catalyst prepared using the incipient-wetness method. To improve the nitric oxide activity, especially at lower temperature, an alternative approach known as the liquid-phase method was applied in preparing the $\mathrm{Mn}-\mathrm{CeO}_{x} / \mathrm{CNT}$ catalyst [83]. Interestingly, excellent NO activity at low reaction temperatures was demonstrated by the developed catalysts. Even at a low catalytic temperature of $80{ }^{\circ} \mathrm{C}$, the $63-85 \%$ NO conversion was still achieved. Soon after, the NO conversion started to rise significantly, nearly up to $100 \%$, as the reaction temperature increased from 120 to $180{ }^{\circ} \mathrm{C}$. The authors also investigated the $\mathrm{Mn}-\mathrm{CeO}_{x} / \mathrm{CNT}$ catalysts at different $\mathrm{Mn} /(\mathrm{Mn}+\mathrm{Ce})$ molar ratios $(0.4$ to 0.6$)$ on the NO removal activity. $0.5 \mathrm{Mn} /(\mathrm{Mn}+\mathrm{Ce})$ molar ratio was found to be the optimum loading amount for $\mathrm{Mn}-\mathrm{CeO}_{x} / \mathrm{CNT}$ catalyst preparation. From the HRTEM images, an uneven shape and fuzzy crystal lattice was identified on the metal nanoflakes suggesting that the $\mathrm{Mn}-\mathrm{CeO}_{x} / \mathrm{CNT}$ catalyst is amorphous in structure. The XRD result confirms only the presence of typical CNT peaks. Both of these features highly contribute towards high $\mathrm{NO}$ activity at low SCR temperature. This conclusion is in agreement with the research work of Tang et al. [84], where amorphous oxides showed greater NO activity compared to oxides with a crystalline structure in SCR at low temperature.

The effect of thermal treatment condition over $\mathrm{MnO}_{x} / \mathrm{CNT}$ catalysts for the SCR of NO was investigated by Wang et al. [55]. The conventional method for CNT-based catalyst preparation always takes place in an inert atmosphere at a high calcination temperature. However, this condition is undesirable since it could disturb the NO activity due to the catalyst mass loss at high calcination temperature [57]. Hence, Wang et al. [55] prepared the $\mathrm{MnO}_{X} / \mathrm{CNT}$ catalysts based on three different thermal conditions; $\mathrm{MnO}_{x} / \mathrm{CNT}-\mathrm{A} 1$ (calcined in air, $250{ }^{\circ} \mathrm{C}$ for $2 \mathrm{~h}$ ),
$\mathrm{MnO}_{x} / \mathrm{CNT}$-A2 (calcined in air, $300{ }^{\circ} \mathrm{C}$ for $50 \mathrm{~min}$ ), and $\mathrm{MnO}_{x} /$ CNT-N3 (calcined in $\mathrm{N}_{2}, 300{ }^{\circ} \mathrm{C}$ for $2 \mathrm{~h}$ ) to examine their catalytic activity in the $\mathrm{NO}$ removal reaction. It was found that $\mathrm{MnO}_{x} / \mathrm{CNT}-\mathrm{A} 1$ (calcined in air at $250^{\circ} \mathrm{C}$ for $2 \mathrm{~h}$ ) demonstrated the highest catalytic activity compared to the sample calcined in air at $300{ }^{\circ} \mathrm{C}$ for $50 \mathrm{~min}$ and the $\mathrm{MnO}_{x} / \mathrm{CNT}$ catalysts (calcined in $\mathrm{N}_{2}$ at $300{ }^{\circ} \mathrm{C}$ for $2 \mathrm{~h}$ ) throughout the entire temperature window. Even at a low reaction temperature of $80{ }^{\circ} \mathrm{C}$, the recorded NO conversion was up to $60 \%$. However, the NO activity declined in both the $\mathrm{MnO}_{x} / \mathrm{CNT}-\mathrm{A} 2$ (calcined in air at $300{ }^{\circ} \mathrm{C}$ for $50 \mathrm{~min}$ ) and $\mathrm{MnO}_{x} / \mathrm{CNT}-\mathrm{N} 3$ (calcined in $\mathrm{N}_{2}$ at $300{ }^{\circ} \mathrm{C}$ for $2 \mathrm{~h}$ ) catalysts. This is greatly associated with the CNTs reducing $\mathrm{MnO}_{x}$ to a lower valence state during the calcination process. Thus, thermal treatment condition plays a vital role in obtaining the best NO removal for CNT-based catalysts in the SCR reaction.

Su et al. [50] modified the catalytic properties of (Mn) species by introducing $\mathrm{MnO}_{x}$ either on the outer CNT surface or on the inner and outer CNT surface for the SCR of NO with $\mathrm{NH}_{3}$. The recorded $\mathrm{NO}_{x}$ conversion was very low over blank CNTs at a reaction temperature ranging from $80{ }^{\circ} \mathrm{C}$ to $300{ }^{\circ} \mathrm{C}$. By introducing a small amount of $\mathrm{Mn}(3 \%)$ to the CNTs, the catalytic activity of $\mathrm{MnO}_{x} / \mathrm{CNTs}$ was improved tremendously at a reaction temperature between 150 and $250^{\circ} \mathrm{C}$. This positive performance may be greatly associated with the oxidation state of $\mathrm{Mn}$ species as well as the interaction type present between the $\mathrm{MnO}_{x}$ species and the surface of CNTs due to the unique structure of the CNTs [85]. According to the $\mathrm{H}_{2}$-TPR result, $\mathrm{MnO}_{x} /$ CNTs with Mn content of $3 \%$ showed a two-step reduction process, as some of the $\mathrm{MnO}_{x}$ was introduced inside the CNT cavities. Meanwhile, the reduction temperature was identified to be at $219^{\circ} \mathrm{C}$ and $418{ }^{\circ} \mathrm{C}$. Meanwhile, the $3 \%$ Mn-out-CNTs 400 peaks were around 440 to $520^{\circ} \mathrm{C}$. Generally, the valance state and electron environment of manganese are two key components that affect the reduction steps and reduction temperature [50]. Previous work done by Cao et al. [86] showed that the amount of electrons found on the inner part of the CNT surface was insufficient compared to the one located on the outside surface. When the metal oxide species are introduced at the side, which lacks electrons, metal oxide will tend to donate more electrons, leading towards easier reduction activity. Other reports by Chen et al. $[87,88]$ reveal that the reduction of $\mathrm{Fe}_{2} \mathrm{O}_{3}$ nanoparticles, which are located inside the cavity, occur at $600{ }^{\circ} \mathrm{C}$ while the reduction of the outer surface of the MWCNTs occur at $800{ }^{\circ} \mathrm{C}$. Therefore, the difference in reduction activity may be associated with the strong interaction between $\mathrm{MnO}_{x}$ nanoparticles with the inner and outer CNT surface. Concurrently, the number of oxygen molecules could be supplied when $\mathrm{MnO}_{x}$ is introduced onto the CNT surface, promoting high SCR activity. 
In another work, Zhang et al. [70] compared the catalytic activity of Mn-Ce species on CNT using an in situ (reflux) method. In this method, poly(sodium 4-styrenesulonate) (PSS) was used as surfactant during the synthesis of the catalyst in order to assist with the dispersion of CNTs in aqueous solution and to maintain its stability. From the experimental activities, it was found that the MnCe@CNTs-R catalyst showed the highest $(>90 \%) \mathrm{NO}$ conversion and most comprehensive reaction temperature $\left(200-350^{\circ} \mathrm{C}\right)$ in comparison with other catalysts prepared using impregnation and mechanically mixed methods. Both MnCe@CNTs-I and MnCe@CNT-M prepared by impregnation and mechanically mixed methods showed a NO conversion of only up to $90 \%$ and $85 \%$, respectively, at a $170{ }^{\circ} \mathrm{C}$ and $200{ }^{\circ} \mathrm{C}$ temperature window. Upon undergoing the characterisation study, the XRD and TEM results showed that prepared MnCe@CNTs-R afforded an excellent dispersion amount of active species on the CNT surface. This phenomenon could be one of the main reasons favouring the outstanding NO activity. Meanwhile, the XPS analysis revealed that the prepared MnCe@CNTs-R catalyst had more active sites, which promoted the $\mathrm{NH}_{3}$-SCR reaction since more $\mathrm{Mn}$ atoms were exposed onto the CNT surface. Besides that, the oxidation process helped oxidised $\mathrm{NO}$ to $\mathrm{NO}_{2}$. This was due to the interaction present between the $\mathrm{MnO}_{x}$ and $\mathrm{CeO}_{x}$ species, resulting in more oxygen vacancy in the MnCe@CNTs- $\mathrm{R}$ catalyst. This rapidly enhanced the SCR reaction, making it faster. The $\mathrm{NH}_{3}-$ TPD analysis shows that the MnCe@CNTs-R catalyst was not only able to demonstrate a large amount of acid content, but also a stronger acid strength. In terms of stability, the MnCe@CNTs-R activity remained constant during the test period $\left(300{ }^{\circ} \mathrm{C}\right)$. However, the NO conversion for both MnCe@CNTs-I and MnCe@CNTs-M slowly reduced over time. Furthermore, MnCe@CNTs-R exhibited high tolerance towards $\mathrm{SO}_{2}$ and $\mathrm{H}_{2} \mathrm{O}$.

Bai et al. [52] studied $\mathrm{CuO}$ supported on CNTs. The catalyst was developed to better understand the catalytic behaviour of CNT-based catalysts especially in reducing the amount of nitric oxide in an SCR reaction. Different amounts of $\mathrm{CuO}$ loadings were studied at a $200{ }^{\circ} \mathrm{C}$ reaction temperature. Apparently, the catalytic activity of the $\mathrm{CuO} / \mathrm{CNT}$ catalyst was observed to rise as the $\mathrm{CuO}$ loading increased from 1 to $10 \mathrm{wt} \%$. About $88.5 \%$ of $\mathrm{NO}$ was converted when $10 \mathrm{wt} \%$ of $\mathrm{CuO}$ loading was introduced into the CNT. Unfortunately, the NO conversion decreased as the amount of $\mathrm{CuO}$ loading became higher than $10 \mathrm{wt} \%$. It is surmised that the reduction in NO activity is mostly due to the aggregation of $\mathrm{CuO}$ particles on top of the CNT surface [54]. The catalytic performance of $10 \mathrm{wt} \%$ $\mathrm{CuO} / \mathrm{CNT}$ was also studied over a 120 to $150{ }^{\circ} \mathrm{C}$ temperature window. The $\mathrm{NO}$ conversion over $10 \mathrm{wt} \% \mathrm{CuO} / \mathrm{CNT}$ catalyst increased as the reaction temperature increased. Approximately
$88.5 \%$ of $\mathrm{NO}$ was converted when the reaction temperature increased to up to $200{ }^{\circ} \mathrm{C}$. However, the conversion activity of NO reduced to $70.5 \%$ when the reaction temperature increased to $250{ }^{\circ} \mathrm{C}$. This result is in accordance with the tendency of $\mathrm{NH}_{3}$ to oxidise at high reaction temperature, leading to a lower reduction of $\mathrm{NO}$ activity [54]. In terms of stability, $10 \mathrm{wt} \%$ $\mathrm{CuO} / \mathrm{CNT}$ catalyst was highly stable at $200{ }^{\circ} \mathrm{C}$ temperature where a great NO conversion efficiency of $88.5 \%$ as well as outstanding catalytic activity at $72 \mathrm{~h}$ of running was also observed. All the features above are just some of the main advantages of using the $\mathrm{CuO} / \mathrm{CNT}$ catalyst in the SCR of NO at low temperature.

Bai et al. [54] investigated the activity of $\mathrm{V}_{2} \mathrm{O}_{5} / \mathrm{CNT}$ catalysts at a low SCR reaction temperature. They found that $\mathrm{V}_{2} \mathrm{O}_{5} / \mathrm{CNT}$ catalysts have higher catalytic activity compared to $\mathrm{V}_{2} \mathrm{O}_{5}$ particles supported on $\mathrm{AC}\left(\mathrm{V}_{2} \mathrm{O}_{5} / \mathrm{AC}\right)$ at $200{ }^{\circ} \mathrm{C}$ reaction temperature. The BET analysis confirms that the CNTs have a lower $\left(220 \mathrm{~m}^{2} / \mathrm{g}\right)$ surface area than $\mathrm{AC}\left(615 \mathrm{~m}^{3} / \mathrm{g}\right)$, indicating that the catalytic properties in CNTs are better than AC because of the former's special structural features [54]. Meanwhile, a study on the effect of $\mathrm{SO}_{2}$ shows that there was no significant conversion of nitric oxide by $\mathrm{V}_{2} \mathrm{O}_{5} / \mathrm{AC}$ either with or without the presence of $\mathrm{SO}_{2}$ in the reaction stream. However, the conversion of nitric oxide momentously increased and became almost linear at a high level of SCR reaction by $\mathrm{V}_{2} \mathrm{O}_{5} / \mathrm{CNT}(0.1-1 \mathrm{wt} \%)$ catalysts in the presence of $\mathrm{SO}_{2}$. This trend implies that the presence of $\mathrm{SO}_{2}$ has helped increase the reduction of $\mathrm{NO}$ over $\mathrm{V}_{2} \mathrm{O}_{5} / \mathrm{CNT}$ catalysts, especially at low SCR temperature. Bai et al. [54] added that the $\mathrm{V}_{2} \mathrm{O}_{5}$ loading is the sole factor influencing the promotional effect of $\mathrm{SO}_{2}$ in the system. Hence, there was a synergistic connection among CNTs and the vanadium species in the catalyst. Unlike in any other study, $\mathrm{SO}_{2}$ usually displays a poisoning rather than a promoting effect. In this study, the $\mathrm{SO}_{2}$ promoting effect is more likely associated with the formation of $\mathrm{SO}_{4}{ }^{2-}$ species on the catalyst surface. These $\mathrm{SO}_{4}{ }^{2-}$ species would act as new acidic sites that help improve $\mathrm{NH}_{3}$ adsorption, thereby promoting the activity of the catalyst. Similar observations were also reported elsewhere [8991]. Therefore, the $\mathrm{V}_{2} \mathrm{O}_{5} / \mathrm{CNT}$ catalyst is justified as one of the most promising catalytic materials for $\mathrm{SCR}$ at low temperature due to the unique promoting effect of $\mathrm{SO}_{2}$.

Wu et al. [61] introduced the idea of implementing CNTs, a by-product obtained from the prior hydrogen production, as supports for the $\mathrm{V}_{2} \mathrm{O}_{5}-\mathrm{WO}_{3}$ catalyst. In their study, the catalysts were prepared via the impregnation method, while ammonia was used as a reducing agent. A characterisation study conducted using TEM analysis revealed that the diameter of the CNTs was around $50 \mathrm{~nm}$, whereas the $\mathrm{V}_{2} \mathrm{O}_{5}-\mathrm{WO}_{3}$ particle size was about $8 \mathrm{~nm}$. A similar observation was found by $\mathrm{Su}$ et al. 
[50]. In their study, Mn/CNT catalysts were used in the SCR activity. The size of the Mn particles was found to be around $8 \mathrm{~nm}$, while the CNT diameters were around $50 \mathrm{~nm}$. Huang et al. [92] used $\mathrm{V}_{2} \mathrm{O}_{5}$ supported on CNTs as the SCR catalyst. Upon study, the size of the metal particle was found to be around $10 \mathrm{~nm}$, while the diameter of the CNTs was between 10 to $100 \mathrm{~nm}$. Meanwhile, the XRD analysis showed that tungsten oxides could not be identified because their particle size was too small to be determined [93]. This indicates that the $\mathrm{WO}_{3}$ particles were evenly dispersed on top of the catalyst surface [94]. In terms of $\mathrm{NO}_{x}$ reduction efficiency, the $\mathrm{V}_{2} \mathrm{O}_{5}-\mathrm{WO}_{3} / \mathrm{CNT}$ catalyst achieved more than $95 \%$ conversion in reaction temperatures of 340 to $400{ }^{\circ} \mathrm{C}$. However, low $\mathrm{NO}_{x}$ activity was observed when the reaction temperature went below $200{ }^{\circ} \mathrm{C}$, which is probably due to the lack of Lewis active sites. Hence, further investigations into lowering the SCR reaction temperature with high $\mathrm{NO}_{x}$ productivity were proposed. A summary of the reaction conditions and NO activity for CNT-based catalyst supports is shown in Table 2.

\section{Activated carbon and activated carbon fibre as a catalyst support}

The discovery of CNTs, AC, and activated carbon fibre (ACF) as catalysts and catalyst supports has been the focus of researchers in NO removal application $[95,96]$. The adsorption ability of both AC and ACF depends highly on its surface area, internal pore structure, surface characteristics, and the presence of functional groups on the pore surface [97]. Tsen et al. [95] evaluated the catalyst performance of coconut shell $\mathrm{AC}$ as a support with several active metals such as $\mathrm{Cu}, \mathrm{Ni}, \mathrm{Co}$, and $\mathrm{Fe}$. The results conclude that NO conversion increased with an increasing atomic number of active components. Sumathi et al. [2] prepared palm shell AC impregnated with several metal oxides ( $\mathrm{Ce}, \mathrm{Ni}, \mathrm{Fe}$, and $\mathrm{V})$. The palm shell support was found to be capable of removing NO gas and further loading with metal oxides increased the conversion reaction due to the increased micropore volume of the palm shell AC. Yoon et al. [98] studied the effect of propellant waste on ACF by impregnation and heat treatment methods. The introduction of a nitrogen functional group by propellant waste promoted the activity removal of NO two-fold to that of the unmodified ACF at low temperature. The SEM analysis reveals that propellant waste was fully oxidised on the ACF surface after being treated at $500{ }^{\circ} \mathrm{C}$. Meanwhile, Zhu et al. [96] modified ACF through lowtemperature oxygen plasma and nitric acid, which are respectively denoted as activated carbon modified by plasma (ACFP) and activated carbon modified by nitric acid (ACFN). The results indicate that the $\mathrm{CeO}_{2}$ species on ACFN produced higher activity than those on ACFP. This is because the surface of $\mathrm{CeO}_{2} / \mathrm{ACFN}$ is more acidic as it was treated with nitric acid and the reaction between $\mathrm{NO}$ and the catalyst surface became more active. Using several characterisation techniques, such as Fourier transform infrared spectroscopy (FTIR), X-ray photoelectron spectroscopy (XPS), and temperature-programmed desorption (TPD), the comparison of the properties for both ACFP and ACFN was clarified. Chuang et al. [18] considered three different methods, i.e., impregnation, polyol, and microwaveheated polyol methods for the synthesis of an economical $\mathrm{Cu} / \mathrm{AC}$ catalyst. Among these methods, the microwave-heated polyol method showed the highest catalytic activity for the $\mathrm{Cu} / \mathrm{AC}$ catalyst with $80.1 \%$ conversion of NO. Analysis using FESEM verified that the $\mathrm{Cu}$ particles on the AC surface were better dispersed compared to the catalysts prepared using the other two methods. Interestingly, the $\mathrm{MnO}_{2} / \mathrm{ACF}$ catalyst prepared by the co-precipitation method appeared to be a promising catalyst, as it can reduce $\mathrm{NO}$ at a temperature as low as $25^{\circ} \mathrm{C}$ [1]. A similar finding was reported by Sousa et al. [99], where the melamine/AC catalyst prepared by impregnation removed NO at a reaction temperature of $25{ }^{\circ} \mathrm{C}$ with a high conversion of $88 \%$. This suggests that the NO removal by AC and ACF could be a serious contributor to sustainable economic growth by offering cost-effective low energy consumption. Although AC and ACF are extremely effective at removing NO due to the combination with certain active components, the investigation into carbon-based supports is still in progress due to some limitations such as the presence of $\mathrm{O}_{2}$, reactivity at low temperature, and also the components of the carbon itself.

Other unique catalyst modifications have also be implemented, especially improvements in the quality of supporting materials. Klinik et al. [100] treated activated carbons with N-compounds and further enhanced the catalyst surface chemical properties with manganase oxides. It was observed that the addition of water into the SCR system reduced NO activity by 10 to $20 \%$ but increased the selectivity of $\mathrm{N}_{2}$. The $\mathrm{N}-\mathrm{AC} / \mathrm{MnO}_{x}$ catalyst can be justified as one of the promising catalysts for SCR-NH reaction since it yields the highest amount of $\mathrm{NO}$ conversion $(\approx 100 \%)$ at an operating temperature between 180 to $220{ }^{\circ} \mathrm{C}$. Boyano et al. [101] prepared a series of vanadium-loaded carbon-coated monoliths treated with different concentrations of acids. The aim was to investigate the effect of distinct oxidative treatment conditions on the $\mathrm{NH}_{3}$-SCR catalytic environment including chemical surface and texture properties. $\mathrm{HNO}_{3}$ treatment resulted in the most outstanding performance. The vanadium-loaded carbon treated with $\mathrm{HNO}_{3}$ acid achieved the highest NO reduction activity, as there was a large amount of carboxyls and lactones present on the catalyst surface. Acid treatment is an important factor that could enhance the performance of NO activity since it is closely related to the density of the surface oxygen group obtained during the oxidation process. Muniz et al. [102] implemented Nomex-based carbon fibres and Kevlar-based carbon fibres for the SCR of $\mathrm{NO}$ with $\mathrm{NH}_{3}$ at low 


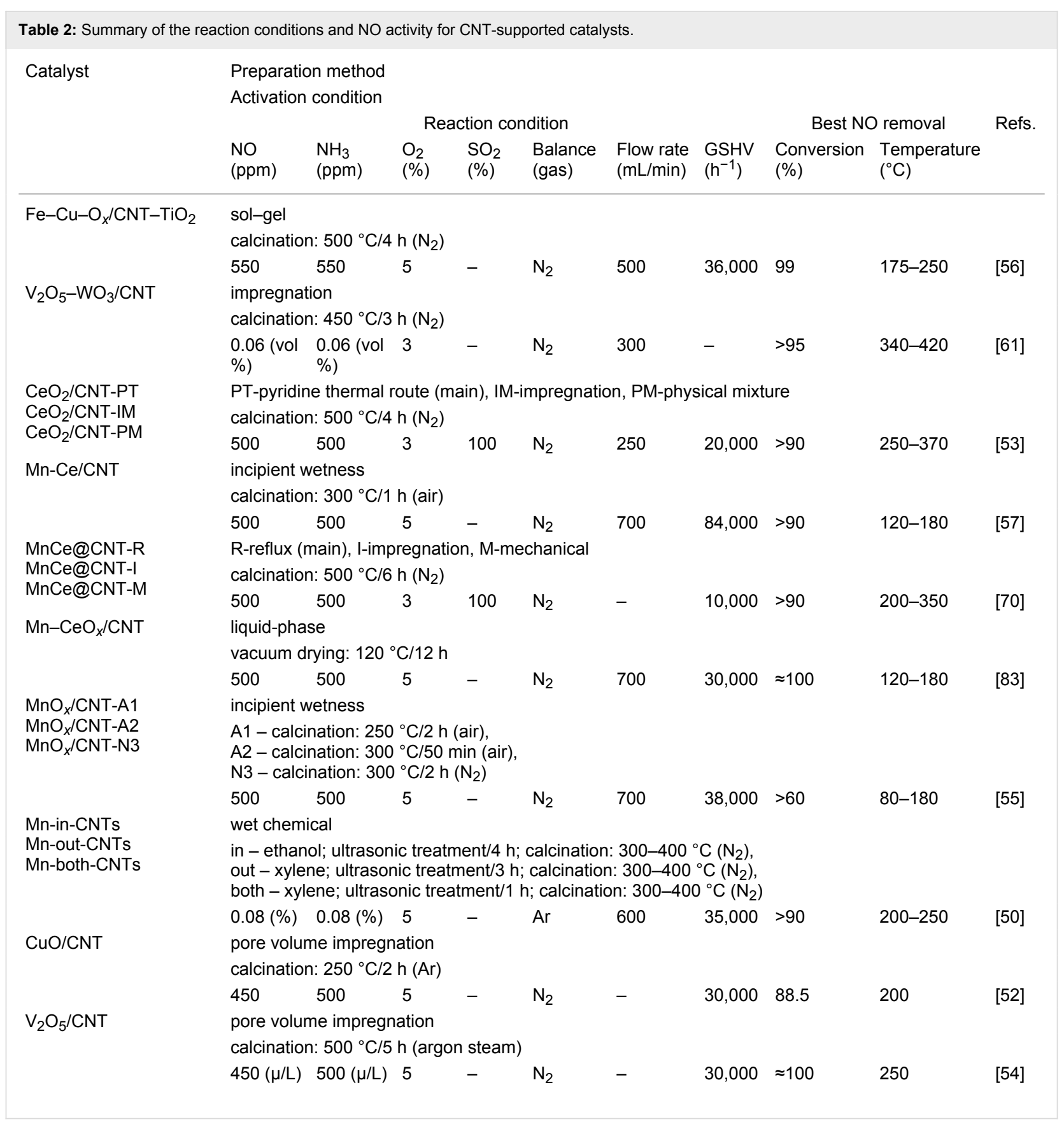

reaction temperature. It was found that the Nomex-based carbon fibres demonstrated a higher degree of NO reduction compared to Kevlar-based carbon fibres due to the presence of the oxygen surface group, which enhances the conversion activity of NO. Lazaro et al. [103] applied vanadium supported onto various forms of AC (powder, briquettes, and monoliths) catalysts via the impregnation method for the SCR of $\mathrm{NO}$ with $\mathrm{NH}_{3}$. All these AC-based catalysts are porous in structure, which plays an important role for achieving high NO removal activity. Galvez et al. [104] prepared a series of activated carbons doped with vanadium compounds, which successfully achieved con- siderable reduction activity of $\mathrm{NO}$ in the presence of $\mathrm{NH}_{3}$ at a reaction temperature between $100-300{ }^{\circ} \mathrm{C}$. A higher NO reduction activity was observed when using a pre-oxidised (SCA750) carbon support. Huang et al. [105] prepared various samples of carbon catalysts from phenol-formaldehyde resins. Each catalyst sample was impregnated with different amounts of $m$-phenyl-enediamine (MPDA) in order to enhance the performance of NO reduction. Upon impregnation of the carbon catalysts with nitrogen, it was observed that the NO catalytic activity increased significantly at operating temperatures below $140{ }^{\circ} \mathrm{C}$. Table 3 summarises the reaction conditions and NO activity for 
activated carbon and activated carbon fibre-based catalyst supports.

\section{Graphene as a catalyst support}

Graphene (GR) is a new outstanding carbon nanomaterial, which demonstrates excellent physiochemical properties such as good thermal conductivity, chemical stability, large surface area, high electron exchange, and a flexible structure [6]. Therefore, GR is considered to have good conductivity at room temperature due to the freely moving electrons on the surface, which can improve the redox performance of the catalyst as well as the catalytic activity in de- $\mathrm{NO}_{x}$ [113]. You et al. [6] verified that high $\mathrm{NO}$ conversion can be achieved over GR at low reaction temperature. $\mathrm{A} \mathrm{MnO}_{x}-\mathrm{CeO}_{2} / \mathrm{GR}$ catalyst prepared

Table 3: Summary on the reaction conditions and NO activity for activated carbon and activated carbon fiber supported based catalysts.

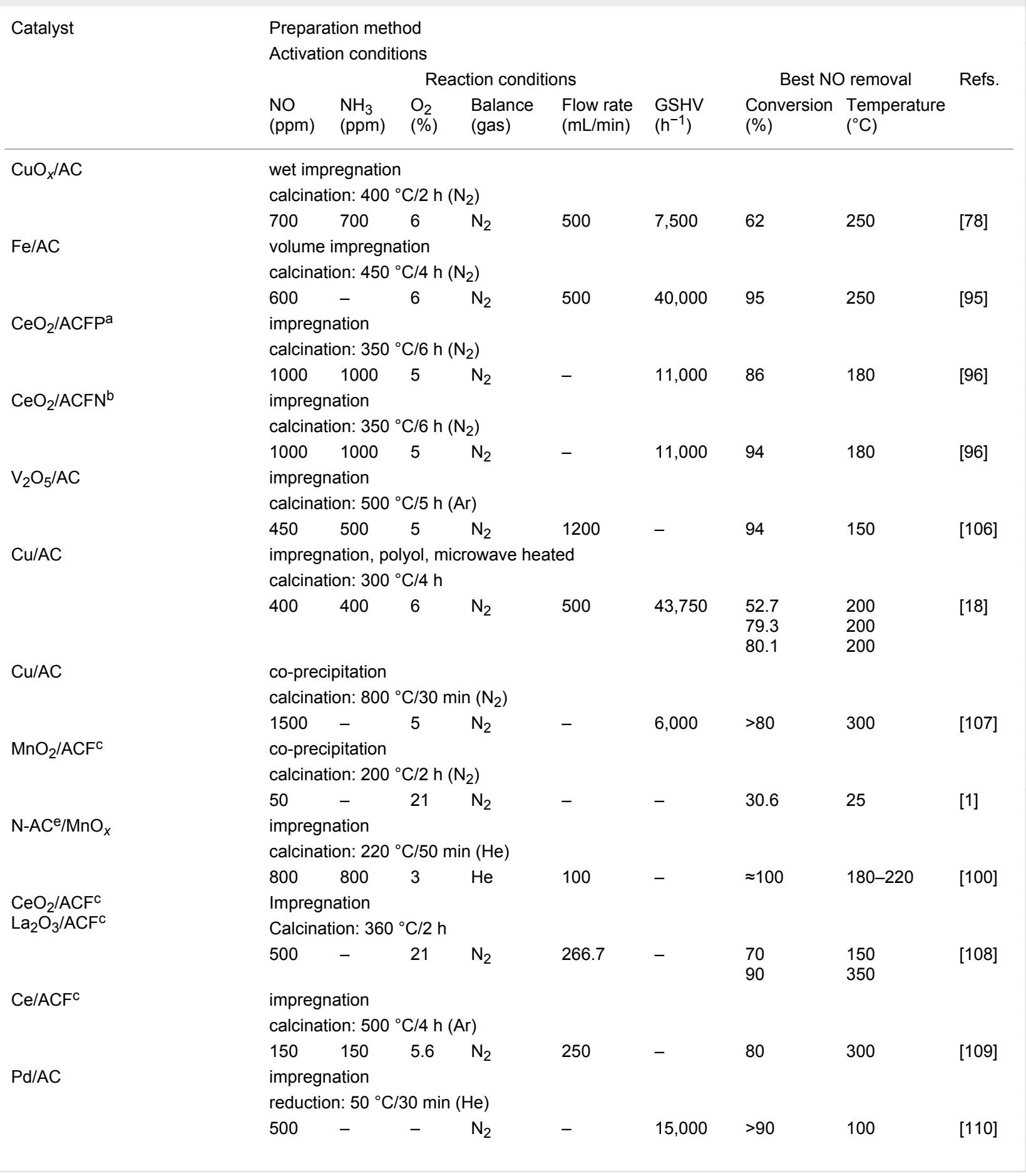




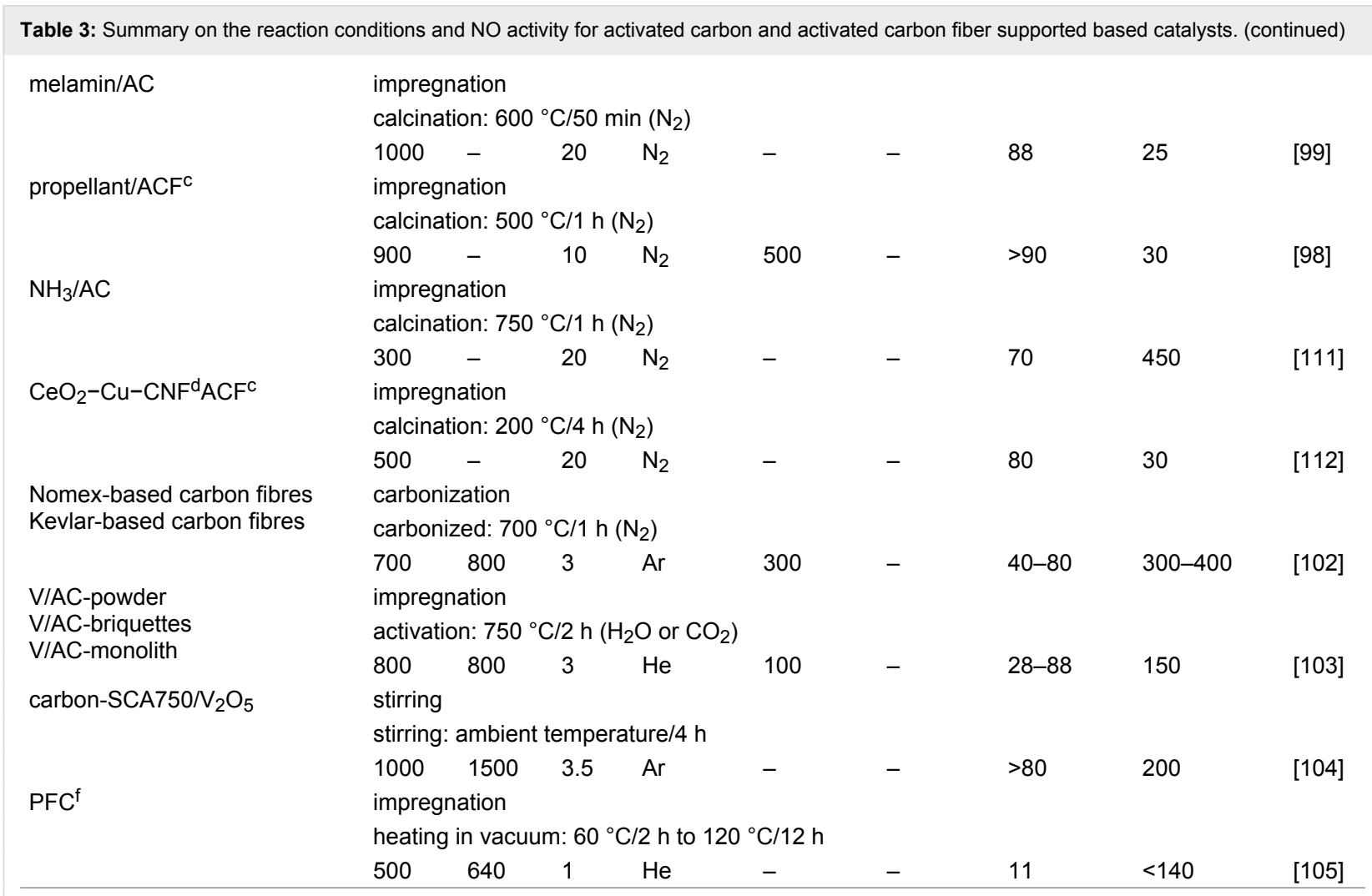

${ }^{a}$ Activated carbon modified by plasma; ${ }^{b}$ activated carbon modified by nitric acid; ${ }^{c}$ activated carbon fiber; ${ }^{d}$ carbon nanofiber; ${ }^{e}$ nitrogen promoted activated carbon; ${ }^{f}$ carbon catalysts from phenol-formaldehyde resins.

via the hydrothermal method yielded high catalytic activity of almost $100 \%$ at $120^{\circ} \mathrm{C}$. The Raman spectra reveal that GR offers more active sites and improves the interaction between $\mathrm{MnO}_{x}$ and $\mathrm{CeO}_{2}$ particles on the flexible GR surface. In fact, Guo et al. [114] explains that the removal of NO can be conducted at room temperature with the addition of graphene oxide (GO) onto carbon nanofibres (CNFs). Xiao et al. [115] used GR to obtain high $\mathrm{NO}$ conversion at low reaction temperature. Their results indicate that the $\mathrm{MnO}_{x}-\mathrm{CeO}_{2} / \mathrm{GR}$ catalyst achieved higher NO conversion compared to pure $\mathrm{MnO}_{x} / \mathrm{GR}$ and $\mathrm{CeO}_{2} / \mathrm{GR}$. The XPS analysis revealed that the addition of GR could change the composition of the Mn species, which plays an important role in electron mobility and thus leading to low reaction temperature in SCR. Moreover, $\mathrm{MnO}_{x}-\mathrm{CeO}_{2} / \mathrm{GR}$ $(0.3 \%)$ at $180{ }^{\circ} \mathrm{C}$ also showed high catalytic activity when $10 \mathrm{vol} \% \mathrm{H}_{2} \mathrm{O}$ and $200 \mathrm{ppm} \mathrm{SO}_{2}$ were added to the system. The same catalytic properties, which convey good resistance towards $\mathrm{H}_{2} \mathrm{O}$ and $\mathrm{SO}_{2}$ poisoning, was also reported by $\mathrm{Lu}$ et al. [116]. The researchers employed $\mathrm{Ce}-\mathrm{Mn} / \mathrm{TiO}_{2}-\mathrm{GE}$ catalysts prepared via the sol-gel and ultrasonic impregnation methods. It was noted that the hydrophobic groups present on the GR surface are not favourable for $\mathrm{H}_{2} \mathrm{O}$ adsorption. Although some researchers achieved good results for catalyst stability and high $\mathrm{H}_{2} \mathrm{O}$ and $\mathrm{SO}_{2}$ resistance, further investigation is still needed to ensure the long-term activity of the prepared catalysts. In addition, there are still limited reports that focus on GR applications for low-temperature SCR. Therefore, there is still a crucial need for more research on catalysts that can provide a reaction temperature as low as room temperature with high NO conversion. Table 4 shows a summary of the reaction conditions and NO activity for graphene-based catalyst supports.

\section{Non-carbon-based materials as catalyst supports for NO removal}

Apart from carbon-based supports, non-carbonious-based materials have also been applied as catalyst supports for nitric oxide removal, especially in the SCR process. Carbon supported materials tend to vaporise easily. This phenomenon would retard the material capability especially during oxidation and hydrogenation reactions [67]. The reproducibility of AC-based catalysts is low since different batches of materials would result in different amounts of ash content [120]. Today, researchers tend to focus on different compound oxides for catalyst support since they possess great features that would result in the higher removal of nitric oxide. Zeolite Socony Mobil-5 (ZSM-5) [62], $\mathrm{TiO}_{2}[37,47,58,59]$, and $\mathrm{Al}_{2} \mathrm{O}_{3}[60]$ are some of the examples of the most frequently used catalyst supports. The ZSM-5 support is reported to have a remarkable ion-exchange capacity 
Table 4: Summary on the reaction conditions and NO activity for graphene supported based catalysts.

\begin{tabular}{|c|c|c|c|c|c|c|c|c|c|}
\hline \multirow[t]{3}{*}{ Catalyst } & \multicolumn{9}{|c|}{ Preparation method } \\
\hline & \multicolumn{6}{|c|}{ Reaction conditions } & \multicolumn{2}{|c|}{ Best NO removal } & \multirow[t]{2}{*}{ Refs } \\
\hline & $\mathrm{NO}(\mathrm{ppm})$ & $\mathrm{NH}_{3}(\mathrm{ppm})$ & $\mathrm{O}_{2}(\%)$ & $\begin{array}{l}\text { Balance } \\
\text { (gas) }\end{array}$ & $\begin{array}{l}\text { Flow rate } \\
(\mathrm{mL} / \mathrm{min})\end{array}$ & $\begin{array}{l}\text { GSHV } \\
\left(\mathrm{h}^{-1}\right)\end{array}$ & $\begin{array}{l}\text { Conversion } \\
(\%)\end{array}$ & $\begin{array}{l}\text { Temperature } \\
\left({ }^{\circ} \mathrm{C}\right)\end{array}$ & \\
\hline \multirow[t]{3}{*}{$\mathrm{CuO}_{x} /$ graphite } & \multirow{2}{*}{\multicolumn{9}{|c|}{$\begin{array}{l}\text { wet impregnation } \\
\text { calcination: } 400^{\circ} \mathrm{C} / 2 \mathrm{~h}\left(\mathrm{~N}_{2}\right)\end{array}$}} \\
\hline & & & & & & & & & \\
\hline & 700 & 700 & 6 & $\mathrm{~N}_{2}$ & 500 & 7,500 & 45 & 250 & {$[78]$} \\
\hline \multirow[t]{3}{*}{ GE/CNF (PGCNF) } & \multirow{2}{*}{\multicolumn{9}{|c|}{$\begin{array}{l}\text { electro-spinning } \\
\text { activation: } 850^{\circ} \mathrm{C} / 10 \mathrm{~min}\left(\mathrm{NH}_{3}\right)\end{array}$}} \\
\hline & & & & & & & & & \\
\hline & 50 & - & 21 & $\mathrm{~N}_{2}$ & - & - & 32.83 & 30 & [114] \\
\hline \multirow{3}{*}{$\begin{array}{l}\text { ACNF } \\
\text { GPNF-1900 } \\
\text { GPNF-2400 }\end{array}$} & \multirow{2}{*}{\multicolumn{9}{|c|}{$\begin{array}{l}\text { electro-spinning } \\
\text { activation: } 800^{\circ} \mathrm{C} / 30 \min \left(\mathrm{N}_{2}\right) \\
\text { graphitized: } 1900^{\circ} \mathrm{C} / 10 \min \left(\mathrm{N}_{2}\right) \\
\text { graphitized: } 2400^{\circ} \mathrm{C} / 10 \min \left(\mathrm{N}_{2}\right)\end{array}$}} \\
\hline & & & & & & & & & \\
\hline & 20 & - & 21 & $\mathrm{~N}_{2}$ & - & - & $\begin{array}{l}11 \\
38 \\
45\end{array}$ & $\begin{array}{l}30 \\
30 \\
30\end{array}$ & [117] \\
\hline \multirow[t]{2}{*}{$\mathrm{MnO}_{x} / \mathrm{TiO}_{2}-\mathrm{GE}^{\mathrm{d}}$} & \multicolumn{9}{|c|}{ ultrasonic impregnation } \\
\hline & 500 & 500 & 7 & $\mathrm{Ar}$ & - & 67,000 & $>93$ & 180 & [113] \\
\hline \multirow[t]{2}{*}{$\mathrm{MnO}_{x}-\mathrm{CeO}_{2} / \mathrm{GR}^{\mathrm{d}}$} & \multicolumn{9}{|c|}{ hydrothermal } \\
\hline & 500 & 500 & 5 & $\mathrm{~N}_{2}$ & - & 24,000 & $\approx 100$ & 120 & [6] \\
\hline \multirow[t]{2}{*}{$\mathrm{CeO}_{x}-\mathrm{MnO}_{x} / \mathrm{TiO}_{2}-\mathrm{GE}^{\mathrm{d}}$} & \multicolumn{4}{|c|}{ calcination: $450^{\circ} \mathrm{C} / 6 \mathrm{~h}\left(\mathrm{~N}_{2}\right)$} & & & & & \\
\hline & 500 & 500 & 7 & $\operatorname{Ar}$ & - & 67,000 & $>99$ & 180 & [116] \\
\hline \multirow[t]{2}{*}{$\mathrm{MnO}_{x} / \mathrm{TiO}_{2}-\mathrm{GO}^{\mathrm{e}}$} & \multicolumn{9}{|c|}{ ultrasonic Impregnation } \\
\hline & 500 & 500 & 7 & $\mathrm{Ar}$ & 600 & 67,000 & $>95$ & 180 & [118] \\
\hline \multirow{2}{*}{$\begin{array}{l}\mathrm{MnO}_{x}-\mathrm{CeO}_{2} / \mathrm{GR}^{\mathrm{d}} \\
\mathrm{MnO}_{x} / \mathrm{GR}^{\mathrm{d}} \\
\mathrm{CeO}_{2} / \mathrm{GR}^{\mathrm{d}}\end{array}$} & \multicolumn{9}{|c|}{ hydrothermal $\left(130{ }^{\circ} \mathrm{C} / 12 \mathrm{~h}\right)$} \\
\hline & 500 & 500 & 5 & $\mathrm{~N}_{2}$ & - & 24,000 & $\begin{array}{l}100 \\
80 \\
20\end{array}$ & $\begin{array}{l}140 \\
140 \\
140\end{array}$ & [115] \\
\hline \multirow[t]{3}{*}{$\mathrm{MnO}_{x} / \mathrm{GR}^{\mathrm{d}}$} & \multicolumn{9}{|c|}{ hydrothermal $\left(160^{\circ} \mathrm{C} / 24 \mathrm{~h}\right)$} \\
\hline & \multicolumn{9}{|c|}{ calcination: $400^{\circ} \mathrm{C} / 2 \mathrm{~h}\left(\mathrm{~N}_{2}\right)$} \\
\hline & $0.06 \%$ & $0.06 \%$ & 3 & $\mathrm{Ar}$ & 500 & 45,000 & $>90$ & 190 & [119] \\
\hline
\end{tabular}

apolyacrylonitrile graphene oxide nanofibers; bactivated carbon nanofibers; ' graphite carbon nanofibers; ${ }^{\mathrm{d}}$ graphene; ${ }^{\mathrm{e}}$ graphene oxide.

[121]. Furthermore, the $\mathrm{TiO}_{2}$ support is known for its high resistance to sulphur poisoning and sulphates, which are much more stable on the $\mathrm{TiO}_{2}$ surface compared to other oxides [47]. In the next sections, a comprehensive review on the non-carbon-based catalyst focusing on the types of supports for SCR reaction is discussed in detail.

\section{ZSM-5 as a catalyst support}

Nowadays, researchers prefer to modify a currently popular ZSM-5 catalyst support by introducing a second metal in order to broaden the temperature window for the SCR reaction. Usually, a second metal is used as an additive. It was found that the interaction between both metals would significantly influence the catalyst surface physiochemical structure $[122,123]$. Ceria is one of the most popular promoters used in metal-containing ZSM-5 catalysts. Many studies have implemented ceria due to its exceptional properties, such as: (i) strong metalsupport interaction that helps increase the dispersion and stability of the metal catalyst; (ii) formation of oxide ion storage and labile oxygen vacancies; (iii) enabling the easy exchange of oxygen molecule with the medium, as the redox couple between the trivalent and tetravalent oxidation states of the ceria ions are present $[124,125]$. Pang et al. [126] reported the high activity and stability of the Ce-Cu/ZSM-5 catalyst. However, 
no attention has been given towards the investigation of redox properties, surface state, or the synergistic effects between $\mathrm{Cu}$ and Ce supported on ZSM-5 in the SCR reaction. Recently, Dou et al. [63] modified Cu/ZSM-5 by introducing Ce into the catalyst. Their main target was to actually develop a catalyst that can broaden the temperature window by focusing on the influence of cerium introduction onto the catalyst structure, acid sites, redox property, and chemical state of $\mathrm{Cu}$ and $\mathrm{Ce}$ species before and after the SCR reaction takes place. The influence of cerium content on the $\mathrm{Cu} / \mathrm{ZSM}-5$ catalyst was evaluated by setting the copper content to $2.0 \mathrm{wt} \%$, and varying the cerium content from $0,0.5,1.0,1.5$ to $2.0 \mathrm{wt} \%$, corresponding to $\mathrm{Cu}-\mathrm{Z}, \mathrm{CuCe} 1-\mathrm{Z}, \mathrm{CuCe} 2-\mathrm{Z}, \mathrm{CuCe} 3-\mathrm{Z}$, and CuCe4-Z, respectively. The experimental results confirm that the temperature window widened to low and high level temperatures when $\mathrm{Ce}$ was introduced into the $\mathrm{Cu} / \mathrm{ZSM}-5$ sample. Of all the $\mathrm{CuCe} /$ ZSM-5 catalysts, CuCe4-Z (where 4 refers to 2.0 wt \% of cerium) demonstrated the best catalytic activity with $95 \% \mathrm{NO}$ being reduced at a $149-427{ }^{\circ} \mathrm{C}$ reaction temperature. In terms of catalytic behaviour, the addition of cerium also helped increase the dispersion of copper onto the support surface (ZSM-5) and also prevented crystallisation, which is prone to happen in SCR reactions. In addition, the redox properties of $\mathrm{CuCe} / \mathrm{ZSM}-5$ catalysts were also improved with the addition of cerium as the second metal. CuCe/ZSM-5 also showed a higher amount of $\mathrm{Cu}$ valence and lattice oxygen compared to the Cu/ZSM-5 catalyst, which are shown from the XPS and $\mathrm{H}_{2}-\mathrm{TPR}$ analysis.

Lou et al. [51] developed a series of Mn/ZSM-5 catalysts for the SCR of NO with ammonia via the precipitation method. The catalysts were prepared at various calcination temperatures (200 to $\left.700{ }^{\circ} \mathrm{C}\right)$, denoted as MnZ-2 $\left(200^{\circ} \mathrm{C}\right), \operatorname{MnZ}-3\left(300^{\circ} \mathrm{C}\right), \mathrm{MnZ}$ $4\left(400{ }^{\circ} \mathrm{C}\right), \operatorname{MnZ}-5\left(500{ }^{\circ} \mathrm{C}\right), \mathrm{MnZ}-6\left(600{ }^{\circ} \mathrm{C}\right)$, and MnZ-7 $\left(70{ }^{\circ} \mathrm{C}\right)$, respectively. The calcination temperature was found to have a significant effect on the NO catalytic activity. If the calcination temperature is too low, the metal salts will tend to decompose incompletely, resulting in a decrease in the amount of active component on the catalyst surface. On the other hand, if the calcination temperature is too high, sintering could occur in the catalyst, which later leads to a serious decrease in the catalyst surface area as well as reduction in the even distribution of active component onto the catalyst [51]. Generally, the calcination temperature is considered to be associated with the manganese oxide final oxidation states, crystallinity, and surface area, which can help determine the success of the NO reduction activity [51]. Limited studies have been done to explore the influences of calcination temperature on Mn/ZSM-5 catalysts. Still, detailed studies on how calcination temperature affects the formation of different $\mathrm{MnO}_{x}$ species in SCR activities have not yet been reported. Therefore, Lou et al. [51] studied the variation of calcination temperature of Mn/ZSM-5 catalysts in order to analyse its effects on the physical and chemical properties of Mn/ZSM-5 catalysts. Mn/ZSM-5 catalysts that were prepared at lower calcination temperatures $\left(<500{ }^{\circ} \mathrm{C}\right)$ resulted in higher Mn surface and lattice oxygen concentration, as well as a larger surface area. Moreover, lower calcination temperatures $\left(<500^{\circ} \mathrm{C}\right)$ promote the SCR Mn/ZSM5 catalyst activity since the formation of $\mathrm{Mn}_{3} \mathrm{O}_{4}$ species and amorphous $\mathrm{MnO}_{2}$ species will react together in the NO reduction process. On the contrary, a higher calcination temperature $\left(600\right.$ to $\left.700{ }^{\circ} \mathrm{C}\right)$ reduced the number of Mn concentration, resulting in smaller surface area and increased crystallinity of the catalysts. This phenomenon will lead to the formation of crystalline $\mathrm{Mn}_{2} \mathrm{O}_{3}$ species, thus reducing the SCR process. Overall, the MnZ-3 (calcined at $300{ }^{\circ} \mathrm{C}$ ) catalyst demonstrated the best performance of NO reduction out of all the Mn/ZSM-5 catalysts. Almost $100 \%$ of NO was converted at a reaction temperature of 150 to $390{ }^{\circ} \mathrm{C}$.

\section{$\mathrm{TiO}_{2}$ as a catalyst support}

Recently, investigations into bimetallic catalysts such as $\mathrm{Fe}-\mathrm{Mn} / \mathrm{TiO}_{2}$ [47,58], $\mathrm{Mn}-\mathrm{Ni} / \mathrm{TiO}_{2}$ [127], $\mathrm{Ce}-\mathrm{W} / \mathrm{TiO}_{2}$ [128], and ternary mixed-oxide catalysts such as $\mathrm{Nb}-\mathrm{Ce}-\mathrm{W} / \mathrm{TiO}_{2}$ [129] and $\mathrm{Zr}-\mathrm{V}-\mathrm{W} / \mathrm{TiO}_{2}$ [130] supported on $\mathrm{TiO}_{2}$ have increased in popularity among scientists. These research studies imply that all these catalysts demonstrate high catalytic activities. For example, the $\mathrm{Mn}-\mathrm{Ni} / \mathrm{TiO}_{2}$ [127] and $\mathrm{Fe}-\mathrm{Mn} / \mathrm{TiO}_{2}$ $[47,58]$ catalysts showed almost $100 \%$ conversion of $\mathrm{NO}$ at low temperature $\left(200{ }^{\circ} \mathrm{C}\right)$ reaction conditions. In addition, the remarkable thermal stability of bimetallic and ternary catalysts has also been recognised. Shi et al. [130] found that the aged $\mathrm{Zr}-\mathrm{V}-\mathrm{W} / \mathrm{TiO}_{2}$ catalyst is more active than the fresh catalyst at a reaction temperature of 150 to $400{ }^{\circ} \mathrm{C}$, after undergoing thermal aging at $750{ }^{\circ} \mathrm{C}$ for $12 \mathrm{~h}$. Lee et al. [131] outlined the applications and synthesis of advanced metal oxide catalysts. They reported that the SCR activities and selectivity were greatly improved with the addition of cerium. This is due to the good thermal stabilities as well as high activities portrayed by the catalysts. Zhang et al. [59] studied the ternary mixed-oxide catalysts for the $\mathrm{SCR}-\mathrm{NH}_{3}$ of $\mathrm{NO}$ reaction. A partial substitution method of metal oxide $\left(\mathrm{M}_{x} \mathrm{O}_{y}, \mathrm{M}=\mathrm{Fe}, \mathrm{Co}, \mathrm{Ni}, \mathrm{Cu}, \mathrm{Sr}, \mathrm{La}\right.$, and Ce) for $\mathrm{V}_{2} \mathrm{O}_{5}$ in the $\mathrm{V}_{2} \mathrm{O}_{5}-\mathrm{WO}_{3} / \mathrm{TiO}_{2}$ catalyst was prepared in accordance to the preparation of ternary mixed-oxide catalysts. The developed $\mathrm{M}_{x} \mathrm{O}_{y}-\mathrm{V}_{2} \mathrm{O}_{5}-\mathrm{WO}_{3} / \mathrm{TiO}_{2}$ catalysts were then tested for SCR- $\mathrm{NH}_{3}$ reaction. At a reaction temperature of above $400{ }^{\circ} \mathrm{C}$, the $\mathrm{M}_{x} \mathrm{O}_{y}-\mathrm{V}_{2} \mathrm{O}_{5}-\mathrm{WO}_{3} / \mathrm{TiO}_{2}$ catalysts increased NO reduction activity. On the other hand, at a reaction temperature below $400{ }^{\circ} \mathrm{C}$, only cobalt oxide substitution increased the NO reduction performance. Of all the partial substitution catalysts, the Co-VW catalyst demonstrated excellent NO reduction activity in SCR- $\mathrm{NH}_{3}$ and resulted in a low yield of $\mathrm{N}_{2} \mathrm{O}$. The Co-VW supported on $\mathrm{TiO}_{2}$ catalyst displayed over $90 \% \mathrm{NO}$ 
conversion at 350 to $495{ }^{\circ} \mathrm{C}$ reaction temperature under a high gas hourly space velocity (GHSV) of $300,000 \mathrm{~h}^{-1}$. In terms of inhibition effect of $\mathrm{H}_{2} \mathrm{O}$ and $\mathrm{SO}_{2}$ on the SCR activity, the substitution of cobalt into the $\mathrm{VW} / \mathrm{TiO}_{2}$ catalyst enhanced the $\mathrm{H}_{2} \mathrm{O}$ and $\mathrm{SO}_{2}$ resistance significantly. From the characterisation studies, the active Co and $\mathrm{V}$ species and $\mathrm{W}$ promoter are observed to be well dispersed on the $\mathrm{TiO}_{2}$ support, after partial substitution of the catalyst. An increase in the amount of surface absorbed oxygen, and Brønsted and Lewis acid sites was observed when Co was introduced into the $\mathrm{VW} / \mathrm{TiO}_{2}$ catalyst. Both the Brønsted and Lewis acid sites were involved in the $\mathrm{SCR}-\mathrm{NH}_{3}$ of $\mathrm{NO}$ reaction. The activity of SCR-NH $\mathrm{NH}_{3}$ within the reaction temperature range was improved, as there was an increment in the number of Lewis and Brønsted acid sites, which is attributed to the Co substitution of V in the catalyst. Hence, unique bimetallic and ternary mixed oxide catalyst has the promising potential as a catalyst for controlling the emission of $\mathrm{NO}_{x}$ from diesel engines.

Generally, low-temperature SCR reactions usually implement manganese oxides $\left(\mathrm{MnO}_{x}\right)$-based catalysts, as they show different types of labile oxygens, which are important for completing the NO catalytic cycle [58]. $\mathrm{MnO}_{x} / \mathrm{TiO}_{2}[132,133]$ and $\mathrm{Mn}$ deposited over carbon-ceramic cellular monolith were reported to be active at low SCR temperature in the presence of oxygen for the successful removal of $\mathrm{NO}$ with $\mathrm{NH}_{3}$ [134]. Ceria $\left(\mathrm{CeO}_{2}\right)$, on the other hand, is known to be inexpensive and nontoxic. It is potentially advantageous compared to many catalytic applications since it has two stable oxidation states, $\mathrm{Ce}^{4+}$ and $\mathrm{Ce}^{3+}$. The redox shift that occurs between $\mathrm{Ce}^{4+}$ and $\mathrm{Ce}^{3+}$ could increase the ease of storing and release of oxygen in ceria. In addition, ceria could also increase the catalyst activity for the SCR-NH 3 of $\mathrm{NO}$ by promoting the oxidisation of $\mathrm{NO}$ to $\mathrm{NO}_{2}$ [135]. Therefore, the mixed oxide $\mathrm{Mn}-\mathrm{Ce}$ catalyst is considered to be one of the potential catalysts for high NO reduction activity at low SCR-NH $\mathrm{N}_{3}$ temperature. Recently, Carja et al. [136] developed a Mn-Ce/ZSM-5 catalyst in aqueous phase. They reported that $75 \%$ to nearly $100 \%$ of NO was converted within a 240 to $500{ }^{\circ} \mathrm{C}$ temperature window. Qi et al. [137] also studied the $\mathrm{Mn}-\mathrm{Ce}$ mixed oxide catalyst, which achived $100 \%$ NO conversion at a reaction temperature of $150{ }^{\circ} \mathrm{C}$. Recently, Wu et al. [58] prepared a series of cerium-modified $\mathrm{MnO}_{x}$ supported onto $\mathrm{TiO}_{2}$ using the sol-gel method. The main objective of the study was to determine the possible catalysts that would result in higher catalytic activities at low operating temperature $\left(<100^{\circ} \mathrm{C}\right)$. It was found that $\mathrm{Ce}-\mathrm{MnO}_{x} / \mathrm{TiO}_{2}$ catalysts demonstrated a high level of $\mathrm{NO}$ activity at low $\mathrm{SCR}-\mathrm{NH}_{3}$ temperature. Of all the cerium-modified $\mathrm{MnO}_{x}$ catalysts, $\mathrm{Ce}(0.07) \mathrm{MnTi}$ showed a high $(80 \%) \mathrm{NO}$ conversion at low $\left(80{ }^{\circ} \mathrm{C}\right) \mathrm{SCR}-\mathrm{NH}_{3}$ temperature with a GHSV of $40,000 \mathrm{~h}^{-1}$. In terms of characterisation studies, the pore volume and BET sur- face area in the $\mathrm{Ce}(0.07) \mathrm{MnTi}$ catalyst is $50 \%$ larger than that of the $\mathrm{Ce}(0) \mathrm{MnTi}$ catalyst. The XPS results confirm that by introducing the $\mathrm{Ce}$ into the catalyst, the chemisorbed oxygen concentration on the catalyst surface could doubly increase. Besides that, the TPR results indicate that the activity of $\mathrm{MnO}_{x} /$ $\mathrm{TiO}_{2}$ could be enhanced, the catalyst oxygen storage improved, and facilitation of oxygen mobility over the catalysts achieved, when $\mathrm{Ce}$ is present together with $\mathrm{MnO}_{x} / \mathrm{TiO}_{2} \cdot \mathrm{NH}_{3}$-TPD justifies that the cerium-modified $\mathrm{MnO}_{x} / \mathrm{TiO}_{2}$ catalyst provides better $\mathrm{NH}_{3}$ chemisorption ability, which improves the SCR activity.

As mentioned previously, the existence of ceria helps in the process of oxidising $\mathrm{NO}$ to $\mathrm{NO}_{2}$, thereby increasing the $\mathrm{NO}$ reduction activity $[58,138,139]$. Unfortunately, pure ceria usually tends to lose its oxygen storage capacity (OSC), ending up in catalyst deactivation, as it is known to be poorly thermostable and undergoes rapid sintering at high reaction temperatures [140,141]. Hence, numerous efforts have been made to address this problem by incorporating another type of metal oxide into the ceria lattice. This would facilitate the formation of mixed oxides or solid solutions [141-143]. Moreover, the catalytic performance of the two mixed oxides will be improved, and a new stable compound with different physiochemical properties and catalytic behaviour can be obtained [140]. Xu et al. [144] developed a $\mathrm{CeO}_{2}-\mathrm{TiO}_{2}$ mixed oxide catalyst for the SCR of $\mathrm{NO}$ with $\mathrm{NH}_{3}$ in the presence of oxygen using the impregnation method. It was found that the catalyst was able to convert only up to $92 \%$ of NO within a 275 to $400{ }^{\circ} \mathrm{C}$ working temperature. Gao et al. [37], on the other hand, applied the sol-gel method to prepare the $\mathrm{CeO}_{2}-\mathrm{TiO}_{2}$ catalysts for $\mathrm{SCR}-\mathrm{NH}_{3}$ of NO. The main focus of the study was to enhance the catalyst performance by achieving better dispersion of ceria onto the $\mathrm{TiO}_{2}$ support. From the activity results, it could be summarised that the $\mathrm{CeO}_{2}-\mathrm{TiO}_{2}$ catalyst prepared by the sol-gel method was highly active in the presence of oxygen. The $\mathrm{CeO}_{2}-\mathrm{TiO}_{2}$ catalyst with a 0.6 mass ratio was found to be the most optimum metal loading value that would result in a high conversion of NO. About 93.4 to $98.6 \%$ of NO was converted at a reaction temperature of $250-450{ }^{\circ} \mathrm{C}$ over the $\mathrm{Ce}(0.6) \mathrm{Ti}$ catalyst. The remarkable performance portrayed by this catalyst is attributed to the strong interaction between $\mathrm{Ce}$ and Ti component. Besides that, the high concentration level of amorphous $\mathrm{Ce}$ on the catalyst surface as well as the increment in the chemisorbed oxygen or/and weakly bonded species, which is a result of the existence of $\mathrm{Ce}^{3+}$ after the introduction of $\mathrm{Ce}$, are also some of the main factors that contribute towards the high catalytic activity.

\section{$\mathrm{Al}_{2} \mathrm{O}_{3}$ as a catalyst support}

Nowadays, gamma alumina $\left(\gamma-\mathrm{Al}_{2} \mathrm{O}_{3}\right)$ has also been used as one of the main supports for SCR catalysts. This material has 
good physiochemical properties such as high specific area, high temperature resistance to inertia in both acid and alkali media, as well as excellent dispersion of the active component [60]. The $\gamma-\mathrm{Al}_{2} \mathrm{O}_{3}$ support is highly suitable for the SCR reaction since SCR is closely associated with the acidity of the catalyst, whereas the $\gamma-\mathrm{Al}_{2} \mathrm{O}_{3}$ surface occupied with both Brønsted and Lewis acid sites can easily absorb alkaline gas $[145,146]$. Recently, numerous types of Ce-based catalysts have been reported, such as $\mathrm{CeO}_{2} / \mathrm{Al}_{2} \mathrm{O}_{3}$ [147], $\mathrm{MnO}_{x}-\mathrm{CeO}_{y} / \gamma-\mathrm{Al}_{2} \mathrm{O}_{3}$ [148], and copper-modified Al-Ce-PILC [149]. Unfortunately, some of the Ce-based catalyst supported on $\mathrm{Al}_{2} \mathrm{O}_{3}$ have poor resistance against sulphur poisoning, which limits their application, especially in marine diesel engines [60]. Recently, many studies have implemented $\mathrm{MoO}_{3}$ as a second metal in the catalyst. $\mathrm{MoO}_{3}$ has a high compatibility with $\mathrm{SO}_{2}$, excellent resistance to arsenic poisoning, promotes the adsorption of ammonia, and has a strong solid acid content that enhances the acidity of the catalyst [150,151]. Liu et al. [152] found that high NO conversion was achieved at a broad temperature range of 300 to $450{ }^{\circ} \mathrm{C}$, when $5 \%$ of $\mathrm{MoO}_{3}$ was loaded onto the $\mathrm{CeO}_{2} / \mathrm{TiO}_{2}$ catalyst. Lietti et al. [153] reported that the NO conversion improved as Mo was added onto the $\mathrm{V}_{2} \mathrm{O}_{5} / \mathrm{TiO}_{2}$ catalyst. Wang et al. [154] suggested that a high NO conversion could be obtained when $\mathrm{MoO}_{3}$ is impregnated with the HZSM-5 zeolite catalyst. Hence, Yan et al. [60] worked on developing a series of $\mathrm{CeO}_{2} / \mathrm{Al}_{2} \mathrm{O}_{3}$ and $\mathrm{CeMo}_{x} \mathrm{O}_{y} / \mathrm{Al}_{2} \mathrm{O}_{3}$ catalysts using an extrusion method in order to study the best catalytic performance of $\mathrm{NO}_{x}$ activity. It was found that the molybdenum additives $\left(\mathrm{CeMo}_{x} \mathrm{O}_{y} / \mathrm{Al}_{2} \mathrm{O}_{3}\right)$ portrayed more excellent catalytic activity than the $\mathrm{CeO}_{2} / \mathrm{Al}_{2} \mathrm{O}_{3}$ catalyst. About $95 \%$ of $\mathrm{NO}$ was converted over 250 to $430{ }^{\circ} \mathrm{C}$

\begin{tabular}{|c|c|c|c|c|c|c|c|c|c|c|}
\hline \multirow[t]{3}{*}{ Catalyst } & \multicolumn{10}{|c|}{$\begin{array}{l}\text { Preparation method } \\
\text { Activation conditions }\end{array}$} \\
\hline & \multicolumn{7}{|c|}{ Reaction conditions } & \multicolumn{2}{|c|}{ Best NO removal } & \multirow[t]{2}{*}{ Refs. } \\
\hline & $\begin{array}{l}\text { NO } \\
\text { (ppm) }\end{array}$ & $\begin{array}{l}\mathrm{NH}_{3} \\
(\mathrm{ppm})\end{array}$ & $\mathrm{O}_{2}(\%)$ & $\begin{array}{l}\mathrm{SO}_{2} \\
(\mathrm{ppm})\end{array}$ & $\begin{array}{l}\text { Balance } \\
\text { (gas) }\end{array}$ & $\begin{array}{l}\text { Flow rate } \\
\text { (mL/min) }\end{array}$ & $\begin{array}{l}\text { GSHV } \\
\left(\mathrm{h}^{-1}\right)\end{array}$ & $\begin{array}{l}\text { Conversion } \\
(\%)\end{array}$ & $\begin{array}{l}\text { Temperature } \\
\left({ }^{\circ} \mathrm{C}\right)\end{array}$ & \\
\hline \multirow[t]{3}{*}{ CuCe/ZSM-5 } & \multicolumn{10}{|c|}{ conventional ion-exchange } \\
\hline & \multicolumn{10}{|c|}{ calcination: $600^{\circ} \mathrm{C} / 4 \mathrm{~h}$} \\
\hline & 1000 & 1000 & 10 & - & $\mathrm{N}_{2}$ & - & 15,000 & 95 & $148-427$ & [63] \\
\hline \multirow{3}{*}{$\begin{array}{l}\mathrm{Mn} / \mathrm{CeTi} \\
\mathrm{Mn} / \mathrm{CeSn}\end{array}$} & \multirow{2}{*}{\multicolumn{10}{|c|}{$\begin{array}{l}\text { inverse co-precipitation } \\
\text { calcination: } 550^{\circ} \mathrm{C} / 5 \mathrm{~h}\end{array}$}} \\
\hline & & & & & & & & & & \\
\hline & 500 & 500 & 5 & 100 & $\mathrm{~N}_{2}$ & - & 60,000 & $>90$ & $175-300$ & [155] \\
\hline \multirow[t]{3}{*}{$\mathrm{M}_{x} \mathrm{O}_{y}-\mathrm{V}_{2} \mathrm{O}_{5}-\mathrm{WO}_{3} / \mathrm{TiO}_{2}$} & \multicolumn{10}{|c|}{ impregnation } \\
\hline & \multicolumn{10}{|c|}{ calcination: $550^{\circ} \mathrm{C} / 3 \mathrm{~h}$ (Air) } \\
\hline & 1000 & 1000 & 10 & - & $\mathrm{N}_{2}$ & 2.51 & 60,000 & $>90$ & $350-495$ & [59] \\
\hline \multirow{3}{*}{$\mathrm{Ce}-\mathrm{MnO}_{x} / \mathrm{TiO}_{2}$} & \multirow{2}{*}{\multicolumn{10}{|c|}{$\begin{array}{l}\text { sol-gel } \\
\text { calcination: } 500^{\circ} \mathrm{C} / 6 \mathrm{~h} \text { (Air) }\end{array}$}} \\
\hline & & & & & & & & & & \\
\hline & 1000 & 1000 & 3 & - & $\mathrm{N}_{2}$ & - & 40,000 & 84 & 80 & {$[58]$} \\
\hline \multirow[t]{3}{*}{$\mathrm{CeMo}_{x} \mathrm{O}_{y} / \mathrm{Al}_{2} \mathrm{O}_{3}$} & \multicolumn{10}{|c|}{ extrusion } \\
\hline & \multicolumn{10}{|c|}{ calcination: $550^{\circ} \mathrm{C} / 2 \mathrm{~h}$ (Air) } \\
\hline & 930 & 930 & 10 & 475 & $\mathrm{~N}_{2}$ & 1200 & 7,200 & $>95$ & $250-430$ & {$[60]$} \\
\hline \multirow[t]{3}{*}{$\mathrm{CeO}_{2}-\mathrm{TiO}_{2}$} & \multicolumn{10}{|l|}{ sol-gel } \\
\hline & \multicolumn{10}{|c|}{ calcination: $500^{\circ} \mathrm{C} / 5 \mathrm{~h}$ (Air) } \\
\hline & 1000 & 1000 & 3 & 200 & $\mathrm{~N}_{2}$ & - & - & 98.6 & $300-400$ & [124] \\
\hline \multirow[t]{3}{*}{ Mn/ZSM-5-t } & \multicolumn{10}{|c|}{ precipitation } \\
\hline & \multicolumn{10}{|c|}{ calcination: $200-700{ }^{\circ} \mathrm{C}$} \\
\hline & 600 & 600 & 4.5 & - & $\mathrm{N}_{2}$ & 300 & 36,000 & $\approx 100$ & 150-390 & {$[51]$} \\
\hline $\mathrm{\gamma}-\mathrm{Fe}_{2} \mathrm{O}_{3}$ & \multicolumn{10}{|c|}{ co-precipitation } \\
\hline \multirow{2}{*}{$\mathrm{\alpha}-\mathrm{Fe}_{2} \mathrm{O}_{3}$} & \multicolumn{10}{|c|}{ calcination: $250^{\circ} \mathrm{C} / 2 \mathrm{~h}\left(\mathrm{\gamma}-\mathrm{Fe}_{2} \mathrm{O}_{3}\right), 500^{\circ} \mathrm{C} / 5 \mathrm{~h}\left(\mathrm{\alpha}-\mathrm{Fe}_{2} \mathrm{O}_{3}\right)$} \\
\hline & 500 & 500 & 3 & - & $\mathrm{N}_{2}$ & 300 & 47,000 & 90 & $200-300$ & [156] \\
\hline \multirow[t]{2}{*}{$\mathrm{Ce}-\mathrm{Sn}-\mathrm{Ti}$} & $\begin{array}{l}\text { inverse } \\
\text { calcina }\end{array}$ & $\begin{array}{l}\text { co-prec } \\
\text { on: } 500\end{array}$ & $\begin{array}{l}\text { itation } \\
\mathrm{C} / 6 \mathrm{~h}\end{array}$ & & & & & & & \\
\hline & 800 & 800 & 5 & 200 & $\mathrm{~N}_{2}$ & 500 & 50,000 & $>90$ & $280-400$ & [157] \\
\hline $\mathrm{Fe}-\mathrm{Mn} / \mathrm{TiO}_{2}$ & $\begin{array}{l}\text { incipien } \\
\text { calcina }\end{array}$ & $\begin{array}{l}\text { wetnes } \\
\text { on: } 500\end{array}$ & $\begin{array}{l}\text { impregna } \\
\mathrm{C} / 6 \mathrm{~h} \text { (Air }\end{array}$ & tion & & & & & & \\
\hline & 1000 & 1000 & 2 & 100 & $\mathrm{~N}_{2}$ & 100 & 30,000 & $\approx 100$ & 120 & [125] \\
\hline
\end{tabular}


working temperature under a GHSV of $7200 \mathrm{~h}^{-1}$. The best calcination temperature for $\mathrm{CeMo}_{x} \mathrm{O}_{y} / \mathrm{Al}_{2} \mathrm{O}_{3}$ catalyst was at $550{ }^{\circ} \mathrm{C}$. The catalyst also demonstrated high resistance towards $\mathrm{H}_{2} \mathrm{O}$ and $\mathrm{SO}_{2}$ poisoning. The following reasons are some of the best features that reflect the promotional effect of molybdenum additives on the SCR-NH 3 catalytic performance of $\mathrm{NO}_{x}$ : (a) the amount of surface acidity increases when molybdenum is used as additive in the catalyst; (b) the specific surface area increases as molybdenum is applied as additive; (c) a higher proportion of $\mathrm{Ce}^{3+} /\left(\mathrm{Ce}^{4+}+\mathrm{Ce}^{3+}\right)$ and $\mathrm{O}_{\alpha} /\left(\mathrm{O}+\mathrm{O}_{\beta}\right)$ on the catalyst surface is produced, which leads to an increment in catalyst activity. Therefore, the $\mathrm{CeMo}_{x} \mathrm{O}_{y} / \mathrm{Al}_{2} \mathrm{O}_{3}$ catalyst can also be applied to control the emission of $\mathrm{NO}_{x}$ in the SCR-NH${ }_{3}$ of $\mathrm{NO}$ reaction. Table 5 summarises the reaction conditions and NO activity of non-carbon-based catalyst supports.

\section{Conclusion}

Carbon-based and non-carbon-based materials as catalyst supports for the selective catalytic reduction (SCR)- $\mathrm{NH}_{3}$ of $\mathrm{NO}$ have been comprehensively studied over the past few decades. The mechanism of SCR is acknowledged as a complex process that follows both the Langmuir-Hinshelwood and the Eley-Rideal mechanisms. The standard SCR usually has a lower reaction rate than the fast SCR, where the high formation of $\mathrm{NO}_{2}$ in the latter contributes more efficiently as an oxidising agent in the redox reaction. The modification of catalyst supports, focusing on their physiochemical properties, was thoroughly reviewed. The preparation method is one of the most crucial factors that affect the nature and dispersion of metal loading onto the catalyst surface. Several methodological procedures such as sol-gel, impregnation, extrusion, reflux, and pyridine-thermal are among the more frequently used methods for achieving high catalytic performance. In this review, the performance of carbon-based materials as catalyst supports, including carbon nanotubes, activated carbon, activated carbon fibre, and graphene on the SCR- $\mathrm{NH}_{3}$ of $\mathrm{NO}$ activity was discussed in detailed. In comparison, non-carbon-based catalyst supports such as $\mathrm{ZSM}-5$, $\mathrm{TiO}_{2}$, and $\mathrm{Al}_{2} \mathrm{O}_{3}$ were also reviewed. In summary, carbon nanotube-based catalyst supports were found to yield the best NO conversion, even at low operating temperatures, out of all of the catalyst supports studied. Pure CNTs yield low NO conversion and have poor resistance to $\mathrm{H}_{2} \mathrm{O}$ and $\mathrm{SO}_{2}$. However, catalyst modification with other metal oxides $\left(\mathrm{CeO}_{x}, \mathrm{MnO}_{x}, \mathrm{FeO}_{x}, \mathrm{CuO}_{x}\right)$ has been proven to be promising in attaining novel catalysts with high $\mathrm{NO}$ reduction activity. Even though many attempts have previously been made, scientists need to conduct more in-depth and far-reaching studies in order to achieve the best NO conversion for actual industrial and power emission applications. Moreover, other suggestions of a technical nature are also important to produce high-end research projects. Further recommendations that can be considered are:
1. Implementing the microwave irradiation technique for activation of CNT-based catalyst supports.

2. Performing a research study on simultaneous removal of $\mathrm{SO}_{2}$ and NO using the best CNT-based supported catalyst.

3. Fundamental study on the electronic interaction between CNTs and metal oxides in the SCR-NH $\mathrm{N}_{3}$ system using a density functional theory (DFT) approach.

\section{Acknowledgements}

This work was supported through the Fundamental Research Grant Scheme (FRGS): 203/PJKIMIA/6071335, and USMNanoMITE Grant (LRGS): 203/PJKIMIA/6720009.

\section{ORCID ${ }^{\circledR}$ iDs}

Abdul Rahman Bin Mohamed - https://orcid.org/0000-0002-5418-5456

\section{References}

1. Wang, M.; Liu, H.; Huang, Z.-H.; Kang, F. Chem. Eng. J. 2014, 256, 101-106. doi:10.1016/j.cej.2014.06.108

2. Sumathi, S.; Bhatia, S.; Lee, K. T.; Mohamed, A. R. J. Hazard. Mater. 2010, 176, 1093-1096. doi:10.1016/j.jhazmat.2009.11.037

3. Liu, C.; Shi, J.-W.; Gao, C.; Niu, C. Appl. Catal., A 2016, 522, 54-69. doi:10.1016/j.apcata.2016.04.023

4. Valdes, S.; Marban, G.; Fuertes, A. B. Appl. Catal., B: Environ. 2003, 46, 261-271. doi:10.1016/S0926-3373(03)00217-0

5. Mrad, R.; Aissat, A.; Cousin, R.; Courcot, D.; Siffert, S. Appl. Catal., A 2015, 504, 542-548. doi:10.1016/j.apcata.2014.10.021

6. You, X.; Sheng, Z.; Yu, D.; Yang, L.; Xiao, X.; Wang, S. Appl. Surf. Sci. 2017, 423, 845-854. doi:10.1016/j.apsusc.2017.06.226

7. Pan, S.; Luo, H.; Li, L.; Wer, Z.; Huang, B. J. Mol. Catal. A: Chem. 2013, 377, 154-161. doi:10.1016/j.molcata.2013.05.009

8. Shan, W.; Song, H. Catal. Sci. Technol. 2015, 5, 4280-4288. doi:10.1039/C5CY00737B

9. Li, J.; Chang, H.; Ma, L.; Hao, J.; Yang, R. T. Catal. Today 2011, 175, 147-156. doi:10.1016/j.cattod.2011.03.034

10. Cao, F.; Su, S.; Xiang, J.; Wang, P.; Hu, S.; Sun, L.; Zhang, A. Fuel 2015, 139, 232-239. doi:10.1016/j.fuel.2014.08.060

11. Li, Y.; Wan, Y.; Li, Y.; Zhan, S.; Guan, Q.; Tian, Y. ACS Appl. Mater. Interfaces 2016, 8, 5224-5233. doi:10.1021/acsami.5b10264

12. Rahmaninejad, F.; Gavaskar, V. S.; Abbasian, J. Appl. Catal., B: Environ. 2012, 119-120, 297-303. doi:10.1016/j.apcatb.2012.03.005

13. Shen, B.; Wang, Y.; Wang, F.; Liu, T. Chem. Eng. J. 2014, 236, 171-180. doi:10.1016/j.cej.2013.09.085

14. Macleod, N.; Lambert, R. M. Appl. Catal., B: Environ. 2002, 35 , 269-279. doi:10.1016/S0926-3373(01)00264-8

15. Pereira, M. V. L.; Nicolle, A.; Berthout, D. Catal. Today 2015, 258, 424-431. doi:10.1016/j.cattod.2015.03.027

16. Jin, R.; Liu, Y.; Wu, Z.; Wang, H.; Gu, T. Chemosphere 2010, 78, 1160-1166. doi:10.1016/j.chemosphere.2009.11.049

17. Lázaro, M. J.; Ascaso, S.; Pérez-Rodríguez, S.; Calderón, J. C.; Gálvez, M. E.; Nieto, M. J.; Moliner, R.; Boyano, A.; Sebastián, D.; Alegre, C.; Calvillo, L.; Celorrio, V. C. R. Chim. 2015, 18, 1229-1241. doi:10.1016/j.crci.2015.06.006 
18. Chuang, K.-H.; Lu, C.-Y.; Wey, M.-Y.; Huang, Y.-N. Appl. Catal., A 2011, 397, 234-240. doi:10.1016/j.apcata.2011.03.003

19. Cha, W.; Ehrman, S. H.; Jurng, J. J. Environ. Chem. Eng. 2016, 4, 556-563. doi:10.1016/j.jece.2015.10.033

20. Nova, I.; Ciardelli, C.; Tronconi, E.; Chatterjee, D.; Bandl-Konrad, B. Catal. Today 2006, 114, 3-12. doi:10.1016/j.cattod.2006.02.012

21. Liu, Z.; Yi, Y.; Zhang, S.; Zhu, T.; Zhu, J.; Wang, J. Catal. Today 2013, 216, 76-81. doi:10.1016/j.cattod.2013.06.009

22. Liu, Z.; Su, H.; Chen, B.; Li, J.; Woo, S. I. Chem. Eng. J. 2016, 229, 255-262. doi:10.1016/j.cej.2016.04.100

23. Xu, H.; Wang, Y.; Cao, Y.; Fang, Z.; Lin, T.; Gong, M.; Chen, Y. Chem. Eng. J. 2014, 240, 62-73. doi:10.1016/j.cej.2013.11.053

24. Wei, Z. S.; Zeng, G. H.; Xie, Z. R.; Ma, C. Y.; Liu, X. H.; Sun, J. L.; Liu, L. H. Fuel 2011, 90, 1599-1603. doi:10.1016/j.fuel.2010.11.021

25. Shi, Y.; Chen, S.; Sun, H.; Shu, Y.; Quan, X. Catal. Commun. 2013, 42, 10-13. doi:10.1016/j.catcom.2013.07.036

26. Chen, L.; Li, J.; Ge, M.; Ma, L.; Chang, H. Chin. J. Catal. 2011, 32, 836-841. doi:10.1016/S1872-2067(10)60195-7

27. Liu, F.; Asakura, K.; He, H.; Liu, Y.; Shan, W.; Shi, X.; Zhang, C. Catal. Today 2011, 164, 520-527. doi:10.1016/j.cattod.2010.10.008

28. Zhang, D.; Zhang, L.; Fang, C.; Gao, R.; Qian, Y.; Shi, L.; Zhang, J. RSC Adv. 2013, 3, 8811-8819. doi:10.1039/c3ra41400k

29. Sohrabi, S.; Akhlaghian, F. J. Nanostruct. Chem. 2016, 6, 93-102. doi:10.1007/s40097-015-0182-x

30. Chong, S.; Zhang, G.; Zhang, N.; Liu, J.; Zhu, Y.; Huang, T.; Fang, S. Ultrason. Sonochem. 2016, 32, 231-240. doi:10.1016/j.ultsonch.2016.03.019

31. Zhang, H.; Chu, W.; Zou, C.; Huang, Z.; Ye, Z.; Zhu, L. Catal. Lett. 2011, 141, 438-444. doi:10.1007/s10562-010-0536-4

32. Yang, Y.; Chiang, K.; Burke, N. Catal. Today 2011, 178, 197-205. doi:10.1016/j.cattod.2011.08.028

33. Dong, Y.; Ren, X.; Wang, M.; He, Q.; Chang, L.; Bao, W. J. Energy Chem. 2013, 22, 783-789. doi:10.1016/S2095-4956(13)60104-7

34. Jeong, B.; Ye, B.; Kim, E.-S.; Kim, H.-D. Catal. Commun. 2017, 93, 15-19. doi:10.1016/j.catcom.2017.01.022

35. Qi, K.; Xie, J.; Fang, D.; Li, F.; He, F. Chin. J. Catal. 2017, 38, 845-852. doi:10.1016/S1872-2067(17)62814-6

36. Nam, K. B.; Kwon, D. W.; Hong, S. C. Appl. Catal., A 2017, 542, 55-62. doi:10.1016/j.apcata.2017.05.017

37. Gao, X.; Jiang, Y.; Zhong, Y.; Luo, Z.; Cen, K. J. Hazard. Mater. 2010, 174, 734-739. doi:10.1016/j.jhazmat.2009.09.112

38. Yeoh, W.-M.; Lee, K.-Y.; Chai, S.-P.; Lee, K.-T.; Mohamed, A. R. J. Phys. Chem. Solids 2013, 74, 1553-1559. doi:10.1016/j.jpcs.2013.05.023

39. Xiong, Z.-b.; Peng, B.; Zhou, F.; Wu, C.; Lu, W.; Jin, J.; Ding, S.-f. Powder Technol. 2017, 319, 19-25. doi:10.1016/j.powtec.2017.06.037

40. Yao, X.; Chen, L.; Kong, T.; Ding, S.; Luo, Q.; Yang, F. Chin. J. Catal. 2017, 38, 1423-1430. doi:10.1016/S1872-2067(17)62868-7

41. Zeng, Y.; Wang, T.; Zhang, S.; Wang, Y.; Zhong, Q. Appl. Surf. Sci. 2017, 411, 227-234. doi:10.1016/j.apsusc.2017.03.107

42. Zhu, L.; Zeng, Y.; Zhang, S.; Deng, J.; Zhong, Q. J. Environ. Sci. 2017, 54, 227-287. doi:10.1016/j.jes.2016.09.014

43. Noor Azeerah, A.; Haliza, A. A.; Zulina, A. M.; Zainab, I. Co-precipitation technology for preparation of solid catalyst in oleochemical processes; MPOB Information Series, Vol. TT-524; 2012.

44. Zhang, Y.; Zheng, Y.; Wang, X.; Lu, X. Catal. Commun. 2015, 62, 57-61. doi:10.1016/j.catcom.2014.12.023
45. Zhang, F.; Zhang, S.; Guan, N.; Schreier, E.; Richter, M.; Eckelt, R.; Fricke, R. Appl. Catal., B: Environ. 2007, 73, 209-219. doi:10.1016/j.apcatb.2006.12.009

46. Sun, P.; Guo, R.-t.; Liu, S.-m.; Wang, S.-x.; Pan, W.-g.; Li, M.-y. Appl. Catal., A 2017, 531, 129-138. doi:10.1016/j.apcata.2016.10.027

47. Qi, G.; Yang, R. T. Appl. Catal., B: Environ. 2003, 44, 217-225. doi:10.1016/S0926-3373(03)00100-0

48. Debecker, D. P.; Hulea, V.; Mutin, P. H. Appl. Catal., A 2013, 451, 192-206. doi:10.1016/j.apcata.2012.11.002

49. Fan, M.-S.; Abdullah, A. Z.; Bhatia, S. ChemCatChem 2009, 1, 192-208. doi:10.1002/cctc.200900025

50. Su, Y.; Fan, B.; Wang, L.; Liu, Y.; Huang, B.; Fu, M.; Chen, L.; Ye, D. Catal. Today 2013, 201, 115-121. doi:10.1016/j.cattod.2012.04.063

51. Lou, X.; Liu, P.; Li, J.; Li, Z.; He, K. Appl. Surf. Sci. 2014, 307, 382-387. doi:10.1016/j.apsusc.2014.04.041

52. Bai, S.; Li, H.; Wang, L.; Guan, Y.; Jiang, S. Catal. Lett. 2014, 144, 216-221. doi:10.1007/s10562-013-1157-5

53. Fang, C.; Zhang, D.; Shi, L.; Gao, R.; Li, H.; Ye, L.; Zhang, J. Catal. Sci. Technol. 2013, 3, 803-811. doi:10.1039/C2CY20670F

54. Bai, S.; Jiang, S.; Li, H.; Guan, Y. Chin. J. Chem. Eng. 2015, 23 , 516-519. doi:10.1016/j.cjche.2014.07.003

55. Wang, X.; Zheng, Y.; Xu, Z.; Liu, X.; Zhang, Y. Catal. Commun. 2014, 50, 34-37. doi:10.1016/j.catcom.2014.02.016

56. Ma, Z.; Yang, H.; Li, Q.; Zheng, J.; Zhang, X. Appl. Catal., A 2012, 427-428, 43-48. doi:10.1016/j.apcata.2012.03.028

57. Wang, X.; Zheng, Y.; Lin, J. Catal. Commun. 2013, 37, 96-99. doi:10.1016/j.catcom.2013.03.035

58. Wu, Z.; Jin, R.; Liu, Y.; Wang, H. Catal. Commun. 2008, 9 , 2217-2220. doi:10.1016/j.catcom.2008.05.001

59. Zhang, Q.-m.; Song, C.-I.; Lv, G.; Bin, F.; Pang, H.-t.; Song, J.-o. J. Ind. Eng. Chem. 2015, 24, 79-86. doi:10.1016/j.jiec.2014.09.012

60. Yan, W.; Shen, Y.; Zhu, S.; Jin, Q.; Liu, Y.; Li, X. Catal. Lett. 2016, 146, 1221-1230. doi:10.1007/s10562-016-1739-0

61. Wu, C.; Sun, X.; Shen, B.; Williams, P. T. J. Energy Inst. 2014, 87, 367-371. doi:10.1016/j.joei.2014.03.024

62. Dou, B.; Lv, G.; Wang, C.; Hao, Q.; Hui, K. Chem. Eng. J. 2015, 270, 549-556. doi:10.1016/j.cej.2015.02.004

63. Muradov, N.; Smith, F.; T-Raissi, A. Catal. Today 2005, 102-103, 225-233. doi:10.1016/j.cattod.2005.02.018

64. Rodgiguez-Reinoso, F. Carbon 1998, 36, 159-175. doi:10.1016/S0008-6223(97)00173-5

65. Santos, A.; Yustos, P.; Quintanilla, A.; García-Ochoa, F. Top. Catal. 2005, 33, 181-192. doi:10.1007/s11244-005-2524-2

66. Auer, E.; Freund, A.; Pietsch, J.; Tacke, T. Appl. Catal., A 1998, 173, 259-271. doi:10.1016/S0926-860X(98)00184-7

67. Stüber, F.; Font, J.; Fortuny, A.; Bengoa, C.; Eftaxiaz, A.; Fabregat, A. Top. Catal. 2005, 33, 3-50. doi:10.1007/s11244-005-2497-1

68. Li, X.; Dong, Z.; Dou, J.; Yu, J.; Tahmasebi, A. Fuel Process. Technol. 2016, 148, 91-98. doi:10.1016/j.fuproc.2016.02.030

69. Samojeden, B.; Grzybek, T. Energy 2016, 116, 1481-1491. doi:10.1016/j.energy.2016.04.059

70. Zhang, D.; Zhang, L.; Shi, L.; Fang, C.; Li, H.; Gao, R.; Huang, L.; Zhang, J. Nanoscale 2013, 5, 1127-1136. doi:10.1039/c2nr33006g

71. Planeix, J. M.; Coustel, N.; Coq, B.; Brotons, V.; Kumbhar, P. S.; Dutarte, R.; Geneste, P.; Bernier, P.; Ajayan, P. M. J. Am. Chem. Soc. 1994, 116, 7935-7936. doi:10.1021/ja00096a076

72. Santillan-Jimenez, E.; Miljković-Kocić, V.; Crocker, M.; Wilson, K. Appl. Catal., B: Environ. 2011, 102, 1-8. doi:10.1016/j.apcatb.2010.09.032 
73. Santillan-Jimenez, E.; Crocker, M.; Bueno-López, A.; Salinas-Martínez de Lecea, C. Ind. Eng. Chem. Res. 2011, 50, 7191-7200. doi:10.1021/ie200054u

74. Luo, J. Z.; Gao, L. Z.; Leung, Y. L.; Au, C. T. Catal. Lett. 2000, 66, 91-97. doi:10.1023/A:1019035220233

75. Long, R. Q.; Yang, R. T. Ind. Eng. Chem. Res. 2001, 40, 4288-4291. doi:10.1021/ie000976k

76. Huang, Z.; Zhu, Z.; Liu, Z.; Liu, Q. J. Catal. 2003, 214, 213-219. doi:10.1016/S0021-9517(02)00157-4

77. Phil, H. H.; Reddy, M. P.; Kumar, P. A.; Ju, L. K.; Hyo, J. S. Appl. Catal., B: Environ. 2008, 78, 301-308. doi:10.1016/j.apcatb.2007.09.012

78. Li, Q.; Yang, H.; Ma, Z.; Zhang, X. Catal. Commun. 2012, 17, 8-12. doi:10.1016/j.catcom.2011.10.008

79. Zhu, Z.; Niu, H.; Liu, Z.; Liu, S. J. Catal. 2000, 195, 268-278. doi:10.1006/jcat.2000.2961

80. Shen, Y.; Zhu, S. Catal. Sci. Technol. 2012, 2, 1806-1810. doi:10.1039/c2cy20238g

81. Jang, S.; Li, J.; Wang, C.; Chen, J.; Ma, L.; Chang, H.; Chen, L.; Peng, Y.; Yan, N. Appl. Catal., B: Environ. 2012, 117-118, 73-80. doi:10.1016/j.apcatb.2012.01.001

82. Wang, L.; Huang, B.; Su, Y.; Zhaou, G.; Wang, K.; Luo, H.; Ye, D. Chem. Eng. J. 2012, 192, 232-241. doi:10.1016/j.cej.2012.04.012

83. Wang, X.; Zheng, Y.; Xu, Z.; Liu, Y.; Wang, X. Catal. Sci. Technol. 2014, 4, 1738-1741. doi:10.1039/C4CY00026A

84. Tang, X.; Hao, J.; Xu, W.; Li, J. Catal. Commun. 2007, 8, 329-334. doi:10.1016/j.catcom.2006.06.025

85. Kijlstra, W. S.; Brands, D. S.; Smit, H. I.; Poels, E. K.; Bliek, A. J. Catal. 1997, 171, 219-230. doi:10.1006/jcat.1997.1789

86. Cao, F.; Zhong, K.; Gao, A.; Chen, C.; Li, Q.; Chen, Q. J. Phys. Chem. B 2007, 111, 1724-1728. doi:10.1021/jp0661037

87. Chen, W.; Pan, X.; Willinger, M.-G.; Su, D. S.; Bao, X. J. Am. Chem. Soc. 2006, 128, 3136-3137. doi:10.1021/ja056721।

88. Chen, W.; Pan, X.; Bao, X. J. Am. Chem. Soc. 2007, 129, 7421-7426. doi:10.1021/ja0713072

89. Zhu, Z.; Liu, Z.; Niu, H.; Liu, S.; Hu, T.; Xie, Y. J. Catal. 2001, 197, 6-16. doi:10.1006/jcat.2000.3052

90. Chen, J. P.; Yang, R. T. J. Catal. 1990, 125, 411-420. doi:10.1016/0021-9517(90)90314-A

91. Chen, J. P.; Yang, R. T. J. Catal. 1993, 139, 277-288. doi:10.1006/jcat.1993.1023

92. Huang, B.; Huang, R.; Jin, D.; Ye, D. Catal. Today 2007, 126, 279-283. doi:10.1016/j.cattod.2007.06.002

93. Buitrago, R.; Ruiz-Martínez, J.; Serrano-Ruiz, J. C.; Rodríguez-Reinoso, F.; Sepúlved-Escribano, A. J. Colloid Interface Sci. 2012, 383, 148-154. doi:10.1016/j.jcis.2012.06.026

94. Zhang, S.; Li, Q.; Zhong, H. Appl. Catal., A: Gen. 2012, 435-436, 156-162. doi:10.1016/j.apcata.2012.05.049

95. Tsen, H.-H.; Lub, C.-Y.; Chang, F.-Y.; Weyd, M.-Y.; Chang, H.-T. Chem. Eng. J. 2011, 169, 135-143. doi:10.1016/j.cej.2011.02.069

96. Zhu, L.; Huang, B.; Wang, W.; Wei, Z.; Ye, D. Catal. Commun. 2011, 12, 394-398. doi:10.1016/j.catcom.2010.10.028

97. Mochida, I.; Koraia, Y.; Shirahama, M.; Kawano, S.; Hada, T.; Seo, Y.; Yoshikawa, M.; Yasutake, A. Carbon 2000, 38, 227-239. doi:10.1016/S0008-6223(99)00179-7

98. Yoon, K. S.; Ryu, S. K. Korean J. Chem. Eng. 2010, 27, 1882-1886. doi:10.1007/s11814-010-0294-4
99. Sousa, J. P. S.; Pereira, M. F. R.; Figueiredo, J. L. Fuel Process. Technol. 2013, 106, 727-733. doi:10.1016/j.fuproc.2012.10.008

100.Klinik, J.; Samojeden, B.; Grzybek, T.; Suprun, W.; Papp, H.; Gläser, R. Catal. Today 2011, 176, 303-308. doi:10.1016/j.cattod.2010.12.009

101.Boyano, A.; Iritia, M. C.; Malpartida, I.; Larrubia, M. A.; Alemany, L. J.; Moliner, R.; Lázaro, M. J. Catal. Today 2008, 137, 222-227. doi:10.1016/j.cattod.2008.02.010

102. Muñiz, J.; Marbán, G.; Fuertes, A. B. Appl. Catal., B: Environ. 1999, 23, 25-35. doi:10.1016/S0926-3373(99)00063-6

103.Lázaro, M. L.; Boyano, A.; Gálvez, M. E.; Izquierdo, M. T.; Garcia-Bordejé, E.; Ruiz, C.; Juan, R.; Moliner, R. Catal. Today 2008, 137, 215-221. doi:10.1016/j.cattod.2007.11.007

104. Gálvez, M. E.; Lázaro, M. J.; Moliner, R. Catal. Today 2005, 102-103, 142-147. doi:10.1016/j.cattod.2005.02.020

105. Huang, M.-C.; Teng, H. Carbon 2003, 41, 951-957. doi:10.1016/S0008-6223(02)00436-0

106. Gao, X.; Liu, S.; Zhang, Y.; Du, X.; Luo, Z.; Cen, K. Catal. Today 2011, 175, 164-170. doi:10.1016/j.cattod.2011.03.058

107.Yang, N.; Yu, J.-I.; Dou, J.-x.; Tahmasebi, A.; Song, H.; Moghtaderi, B.; Lucas, J.; Wall, T. Fuel Process. Technol. 2016, 152, 102-107. doi:10.1016/j.fuproc.2016.06.010

108.Lua, P.; Li, C.; Zenga, G.; Heb, L.; Penga, D.; Cuia, H.; Li, S.; Zhai, Y. Appl. Catal., B: Environ. 2010, 96, 157-161. doi:10.1016/j.apcatb.2010.02.014

109.Athappan, A.; Sattler, M. L.; Sethupathi, S. J. Environ. Chem. Eng. 2015, 3, 2502-2513. doi:10.1016/j.jece.2015.08.028

110.Castegnaro, M. V.; Killian, A. S.; Baibich, I. M.; Alves, M. C. M.; Morais, J. Langmuir 2013, 29, 7125-7133. doi:10.1021/la401460c

111. Rathrore, R. S.; Srivastava, D. K.; Agarwal, A. K.; Verma, N. J. Hazard. Mater. 2010, 173, 211-222. doi:10.1016/j.jhazmat.2009.08.071

112. Talukdar, P.; Bhaduri, B.; Verma, N. Ind. Eng. Chem. Res. 2014, 53, 12537-12547. doi:10.1021/ie502043e

113.Lu, X.; Song, C.; Chang, C.-C.; Yeng, Y.; Tong, Z.; Tang, X. Ind. Eng. Chem. Res. 2014, 53, 11601-11610. doi:10.1021/ie5016969

114.Guo, Z.; Wang, M.; Huang, Z.-H.; Kang, F. Carbon 2015, 87, 282-291. doi:10.1016/j.carbon.2015.02.037

115.Xiao, X.; Sheng, Z.; Yang, L.; Dong, F. Catal. Sci. Technol. 2016, 6, 1507-1514. doi:10.1039/C5CY01228G

116.Lu, X.; Song, S.; Jia, C.; Tong, Z.; Tang, X.; Teng, Y. Chem. Eng. J. 2015, 260, 776-784. doi:10.1016/j.cej.2014.09.058

117.Wang, M.-X.; Huang, Z.-H.; Shen, K.; Kang, F.; Liang, K. Catal. Today 2013, 201, 109-114. doi:10.1016/j.cattod.2012.05.050

118.Su, W.; Lu, X.; Jia, S.; Wang, J.; Ma, H.; Xing, Y. Catal. Lett. 2015, 145, 1446-1456. doi:10.1007/s10562-015-1550-3

119. Jiao, J.-Z.; Li, S.-H.; Huang, B.-C. Acta Phys.-Chim. Sin. 2015, 31, 1383-1390. doi:10.3866/PKU.WHXB201504292

120. Fidalgo, B.; Menéndez, J. A. Chin. J. Catal. 2011, 32, 207-216. doi:10.1016/S1872-2067(10)60166-0

121.Greenhalgh, B.; Fee, M.; Dobri, A.; Moir, J.; Burich, R.; Charland, J.-P.; Stanciulescu, M. J. Mol. Catal. A: Chem. 2010, 333, 121-127. doi:10.1016/j.molcata.2010.10.008

122.Liu, F.; He, H.; Ding, Y.; Zhang, C. Appl. Catal., B: Environ. 2009, 93, 194-204. doi:10.1016/j.apcatb.2009.09.029

123.Picasso, G.; Gutiérrez, M.; Pina, M. P.; Herguido, J. Chem. Eng. J. 2007, 126, 119-130. doi:10.1016/j.cej.2006.09.005 
124. Katta, L.; Sudarsanam, P.; Thrimurthulu, G.; Reddy, B. M. Appl. Catal., B: Environ. 2010, 101, 101-108. doi:10.1016/j.apcatb.2010.09.012

125.Laguna, O. H.; Sarria, F. R.; Centeno, M. A.; Odriozola, J. A. J. Catal. 2010, 276, 360-370. doi:10.1016/j.jcat.2010.09.027

126.Pang, L.; Fan, C.; Shao, L.; Song, K.; Yi, J.; Cai, X.; Wang, J.; Kang, M.; Li, T. Chem. Eng. J. 2014, 253, 394-401. doi:10.1016/j.cej.2014.05.090

127. Thirupathi, B.; Smirniotis, P. G. Catal. Lett. 2011, 141, 1399-1404 doi:10.1007/s10562-011-0678-z

128.Shan, W.; Liu, F.; He, H.; Shi, X.; Zhang, C. Appl. Catal., B: Environ. 2012, 115-116, 100-106. doi:10.1016/j.apcatb.2011.12.019

129.Ma, Z.; Weng, D.; Wu, X.; Si, Z.; Wang, B. Catal. Commun. 2012, 27, 97-100. doi:10.1016/j.catcom.2012.07.006

130.Shi, A.; Wang, X.; Yu, T.; Shen, M. Appl. Catal., B: Environ. 2011, 106, 359-369. doi:10.1016/j.apcatb.2011.05.040

131.Lee, D. W.; Yoo, B. R. J. Ind. Eng. Chem. 2014, 20, 3947-3959. doi:10.1016/j.jiec.2014.08.004

132.Wu, Z.; Jiang, B.; Liu, Y.; Zhao, W.; Guan, B. J. Hazard. Mater. 2007, 145, 488-494. doi:10.1016/j.jhazmat.2006.11.045

133. Ettireddy, P. R.; Ettireddy, N.; Mamedov, S.; Boolchand, P.; Smirniotis, P. G. Appl. Catal., B: Environ. 2007, 76, 123-134. doi:10.1016/j.apcatb.2007.05.010

134.Valdés-Solís, T.; Marbán, G.; Fuertes, A. B. Catal. Today 2001, 69, 259-264. doi:10.1016/S0920-5861(01)00378-9

135.Qi, G.; Yang, R. T.; Chang, R. Appl. Catal., B: Environ. 2004, 51, 93-106. doi:10.1016/j.apcatb.2004.01.023

136. Carja, G.; Kameshima, Y.; Okada, L.; Madhusoodana, C. D. Appl. Catal., B: Environ. 2007, 73, 60-64. doi:10.1016/j.apcatb.2006.06.003

137. Qi, G.; Yang, R. T. J. Catal. 2003, 217, 434-441. doi:10.1016/S0021-9517(03)00081-2

138.Long, R. Q.; Yang, R. T. Appl. Catal., B: Environ. 2000, 27, 87-95. doi:10.1016/S0926-3373(00)00140-5

139.Long, R. Q.; Tang, R. T. J. Am. Chem. Soc. 1999, 121, 5595-5596. doi:10.1021/ja9842262

140.Reddy, N. M.; Khan, A.; Yamada, Y.; Kobayashi, T.; Loridant, S.; Volta, J.-C. J. Phys. Chem. B 2003, 107, 5162-5167. doi:10.1021/jp0344601

141.Luo, M.; Chen, J.; Chen, L.; Lu, L.; Feng, Z.; Li, C. Chem. Mater. 2001, 13, 197-202. doi:10.1021/cm000470s

142.Reddy, B. M.; Laskmanan, P.; Khan, A. J. Phys. Chem. B 2004, 108, 16855-16863. doi:10.1021/jp047217q

143.Wu, Z.; Jiang, B.; Liu, Y.; Wang, H.; Jin, R. Environ. Sci. Technol. 2007, 41, 5812-5817. doi:10.1021/es0700350

144.Xu, W.; Yu, Y.; Zhang, C.; He, H. Catal. Commun. 2008, 9 , 1453-1457. doi:10.1016/j.catcom.2007.12.012

145. Yan, S.; Wang, X.; Wang, W.; Liu, Z.; Niu, J. J. Nat. Gas Chem. 2012, 21, 332-338. doi:10.1016/S1003-9953(11)60373-3

146. Tonetto, G. M.; Damiani, D. E. J. Mol. Catal. A: Chem. 2003, 202, 289-303. doi:10.1016/S1381-1169(03)00214-0

147.Shen, Y.; Zhu, S.; Qiu, T.; Shen, S. Catal. Commun. 2009, 11, 20-23. doi:10.1016/j.catcom.2009.08.001

148.Qu, L.; Li, C.; Zeng, G.; Zhang, M.; Fu, M.; Ma, J.; Zhan, F.; Luo, D. Chem. Eng. J. 2014, 242, 76-85. doi:10.1016/j.cej.2013.12.076

149.Lin, Q.; Hao, J.; Li, J.; Ma, Z.; Lin, W. Catal. Today 2007, 126, 351-358. doi:10.1016/j.cattod.2007.06.007

150.Djerad, S.; Crocoll, M.; Kureti, S.; Tifouti, L.; Weisweiler, W. Catal. Today 2006, 113, 208-214. doi:10.1016/j.cattod.2005.11.067
151.Djerad, S.; Tifouti, L.; Crocoll, M.; Weisweiler, W. J. Mol. Catal. A: Chem. 2004, 208, 257-265. doi:10.1016/j.molcata.2003.07.016

152.Liu, Z.; Zhang, S.; Li, J.; Ma, L. Appl. Catal., B: Environ. 2014, 144, 90-95. doi:10.1016/j.apcatb.2013.06.036

153.Lietti, L.; Nova, I.; Ramis, G.; Dall'Acqua, L.; Busca, G.; Giamello, E.; Forzatti, P.; Bregani, F. J. Catal. 1999, 187, 419-435. doi:10.1006/jcat.1999.2603

154.Wang, X.; Yu, S.; Yang, H.; Zhang, S. Appl. Catal., B: Environ. 2007, 71, 246-253. doi:10.1016/j.apcatb.2006.09.014

155.Xiong, Y.; Tang, C.; Tao, X.; Zhang, L.; Li, L.; Wang, X.; Deng, Y.; Gao, F.; Dong, L. Appl. Catal., A 2015, 495, 206-216. doi:10.1016/j.apcata.2015.01.038

156.Liu, C.; Yang, S.; Ma, L.; Peng, Y.; Hamidreza, A.; Chang, H.; Li, J. Catal. Lett. 2013, 143, 697-704. doi:10.1007/s10562-013-1017-3

157. Yu, M.; Li, C.; Zeng, G.; Zhou, Y.; Zhang, X.; Xie, Y. Appl. Surf. Sci. 2015, 342, 174-182. doi:10.1016/j.apsusc.2015.03.052

\section{License and Terms}

This is an Open Access article under the terms of the Creative Commons Attribution License (http://creativecommons.org/licenses/by/4.0), which permits unrestricted use, distribution, and reproduction in any medium, provided the original work is properly cited.

The license is subject to the Beilstein Journal of

Nanotechnology terms and conditions:

(https://www.beilstein-journals.org/bjnano)

The definitive version of this article is the electronic one which can be found at: doi:10.3762/bjnano.9.68 